\title{
Potential Agricultural and Biomedical Applications of Cold Atmospheric Plasma-Activated Liquids With Self-Organized Patterns Formed at the Interface
}

\author{
Zhitong Chen ${ }^{\circledR}$, Member, IEEE, Rong-Guang $\mathrm{Xu}^{\circledR}$, Peijian Chen, and Qiu Wang
}

\begin{abstract}
Cold atmospheric plasma (CAP) has become a topical research area due to its diverse applications in agriculture, medicine, environment, materials, energy, nanotechnology, and other fields. Plasmas in contact with liquids form marked sensitivity patterns at the interface depending on controlling parameters, including gas species, driving current, gas flow rate, gap length, and electrolyte conductivity. This review overviews basic aspects of plasmas inducing self-organization including computational and experimental studies and potential applications of such plasmas-treated liquids in agriculture and medicine. Representative experimental evidence of self-organized pattern (SOP) in diverse types of plasma discharges is reviewed. Generation and transport of reactive species in SOP plasma and SOP plasma interacting with liquids are introduced and discussed from their potential applications in agriculture and medicine.
\end{abstract}

Index Terms-Cold atmospheric plasma (CAP), food safety, plasma agriculture, plasma medicine, plasma-treated liquids, self-organized pattern (SOP).

\section{INTRODUCTION}

$\mathbf{I}^{\mathrm{N}}$ $\mathrm{N}$ GENERAL, self-organization is related to the spontaneous transition process from a stable state to a pattern in a spatially extended system [1]. It is fascinating and complex phenomena generally observed in both technological and natural contexts, within multiple varieties of physics, chemistry, and biology [2], [3]. Representative examples of self-organization phenomena are those studied in magnetohydrodynamics (MHD) stability and fluid dynamics, such as Rayleigh-Bénard convection and Taylor-Couette flow [4], which are responding to reaction-diffusion systems. Patterns

Manuscript received May 21, 2020; revised August 14, 2020; accepted August 24, 2020. The work of Qiu Wang was supported by the State Key Laboratory of High Temperature Gas Dynamics Youth Innovation Fund under Grant LHD2019CX10. The review of this article was arranged by Senior Editor S. J. Gitomer. (Corresponding author: Qiu Wang.)

Zhitong Chen and Rong-Guang Xu are with the Department of Mechanical and Aerospace Engineering, The George Washington University, Washington, DC 20052 USA.

Peijian Chen is with the State Key Laboratory for Geomechanics and Deep Underground Engineering, School of Mechanics and Civil Engineering, China University of Mining and Technology, Xuzhou 221116, China.

Qiu Wang is with the State Key Laboratory of High Temperature Gas Dynamics, Institute of Mechanics, Chinese Academy of Sciences, Beijing 100190, China (e-mail: wangqiu@imech.ac.cn).

Color versions of one or more of the figures in this article are available online at http://ieeexplore.iee.org.

Digital Object Identifier 10.1109/TPS.2020.3019995 are produced by activator inhibitor modes [5], [6], which share important similarities with plasma system-generating patterns [7]. The patterns formed at the interfaces are luminous plasma filaments displaying particle-like behavior, such as generation, dynamics, annihilation, scattering, and collective effects resulting into self-organized structures. The plasmas are formed and sustained by electron multiplication in the volume, combined with secondary electron emission by the dielectric surfaces. SOPs appear due to filamentary discharges first forming where memory charges have been previously deposited, while discharges cannot form in the vicinity of these filaments. This mechanism of activation-inhibition results into filament patterns which are typical of reaction-diffusion systems. Various types of self-organization phenomena have been addressed in a number of plasmas, such as dielectric barrier discharge (DBD), gas flow stabilized discharges, high-frequency discharge, discharges with liquid electrodes, and resistively stabilized discharged [8]-[12]. According to Müller, patterns of spots occur if a layer (electrode) contacts with a resistive medium, and it is associated with Sshaped voltage-current characteristics [13]. Many articles on numerical models have indicated that the crucial feature of the analysis is bifurcation theory [14]-[16]. Although numerical models for the self-organized pattern (SOP) formation in discharge plasma have been proposed, the experimental conditions for SOP formation have not been completely clarified. Bruggeman et al. [17] employed the electrical and optical diagnostics to investigate atmospheric glow discharges with the liquid anode. Wilson et al. [19] noticed a self-rotating atmospheric discharge with low current between a water anode and a metallic cathode generating a ring-like anode spot, which was one similarly observed by Miao et al. [18]. Li et al. [20] studied spotted anode layers in a glow discharge at atmospheric pressure with miniature argon flow and a water electrode. Upon varying gap width and discharge current, several SOPs were observed on the anode layer in glow discharge at atmospheric pressure, such as singlering, diffuse-disk, wheel-spokes, disk-ring, and radial-stripes patterns. Gaisin [21] studied the electrical characteristics of large current discharges with a liquid anode. The effects on electrolyte composition/concentration, interelectrode spacing, current, and the diameter of the metal cathode were elucidated, 
and different discharge SOPs were observed. Laroussi and $\mathrm{Lu}$ elucidated ac-driven discharges between a water electrode and a metal disk, and noticed distinctive patterns that depend on the electrodes' polarity [22]. During the plasma process, SOP is important to extend applications of plasma-liquid interactions [23]-[25]. Recently, lots of plasma discharges at the liquid surface/interface have been investigated related to applications including nanoparticle and materials synthesis, agriculture, foods, medicine, and others [26]-[31].

In addition, the treatment of liquid media with plasma generates plasma-treated liquids that maintain the major biological effect of plasma containing ROS and RNS [32], [33]. The complexity of reactive species in plasma-treated solutions with their reactivity and stability not only gives a challenge but also establishes plasma-treated liquids as a synergistic and unique sterilized and therapeutic approach [34], [35]. The main aim of this review is to summarize fundamental aspects of SOP plasma and to describe their potential applications in agriculture, food safety, and biomedicine. To this end, theoretical, computational, and experimental studies of SOPs in plasma discharges are presented and analyzed. This review is organized as follows. Section II elucidates the general concepts and experimental investigations of plasma selforganization. Section III considers the theoretical modeling of self-organization in plasma discharges. Some theoretical methods employed for the study of SOP formation are presented, and followed by established plasma discharge models. Section IV addresses the mechanisms of SOP plasma-treated liquids. Section V explains the potential agricultural applications of SOP plasma-treated liquids. Section VI the overviews biomedical potential applications of SOP plasma-treated liquids. This review ends with a conclusion and an outlook.

\section{Self-Organization in Plasma Discharges}

Plasma self-organization is more often observed at interphases, such as those over the solid and liquid electrodes [36]. SOPs in plasma discharges on liquid surfaces are more recognizable, especially when conductive liquid acts as an anode or a cathode. Moreover, plasma above the liquid is characterized by two distinctive phenomena: local (across the interface) and global (along with the interface). A representative depiction of plasma discharges between liquid and a metal pin is presented in Fig. 1(a). It is obvious that the typical plasma structure is a glow discharge with an anode glow (AG) region, a positive column (PC), a Faraday dark space (FDS), a negative glow $(\mathrm{NG})$, and a cathode fall $(\mathrm{CF})$. Many features are similar to atmospheric glow discharge between liquid/solid electrodes, suggesting that this discharge is the normal glow with an atmospheric version [36]. Plasma-liquids interphase is subject to perturbations. The phase change of the electrode material is generally neglected in the solid electrode research, while these phenomena might play a major role in discharges with liquid electrodes. In addition, while reactive species seldom interact below and across the surface in plasma-materials processing, which might be solvated and react in the liquid [4]. Representative different anode patterns are shown in Fig. 1(b). The obtained self-organization patterns include square/hexagonal
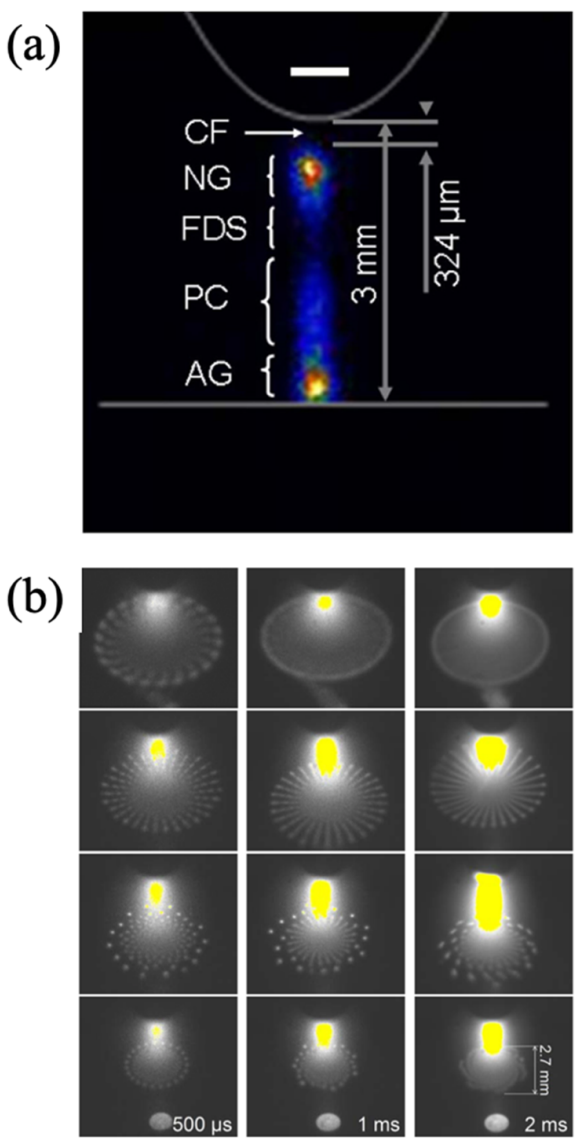

Fig. 1. (a) Single-shot photograph of the discharge structure with the liquid anode (reproduced from [17]). (b) Anode patterns generated at different conductivities and exposure times (reproduced from [39]).

superlattices, square-lattices, square-textures, hollow hexagonal, rotating-wheels, and multiarmed spirals [37], [38]. The formation of these patterns depends on the number of spots that can form stripe patterns.

Fig. 2 presents the effect of discharge current, voltage, and air gap on SOP plasma. In Fig. 2(a), a schematic representation of the glow discharge setup is capable of producing welldefined SOPs at the liquid interface. Anode (thin copper plate, thickness: $0.2 \mathrm{~mm}$, and diameter: $22 \mathrm{~mm}$ ) was placed at the bottom. About 6-mL DI (deionized) water was added to the well. The tungsten cathode (diameter: $2 \mathrm{~mm}$ ) was then set above the DI water surface. A ballast resistor $(90 \mathrm{k} \Omega$ ) was connected between the cathode and the DC power supply unit. Voltage is applied between cathode and liquid anode, and a small (1-2 mm) gap between the cathode and liquid surface accommodated a bunch of SOPs plasma. In Fig. 2(a), the current-voltage characteristics affecting SOPs are divided into four stages. Stage I: a single filament following the initial corona discharge; Stage II: drastically enhanced heat radiation; Stage III (transition stage): an unstable state; and Stage IV: the multifilament pattern. At stage IV, the discharge plasma stretches out to a large number of discharge filaments and stabilizes at the multifilament stage at liquid media surface (SOPs). Complex shapes consisting of confocal and radial lines with different densities can be generated, and elements of axial/radial symmetry can be seen. Current and electrolyte 
(a)

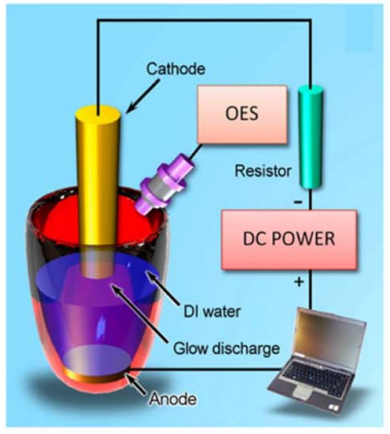

(b)

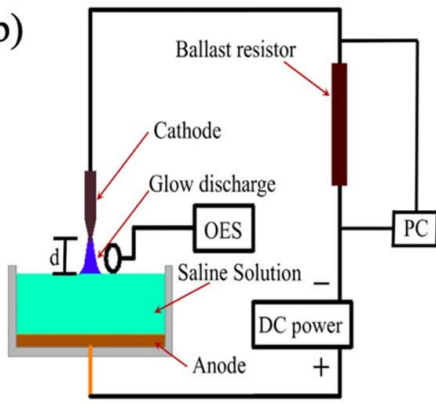

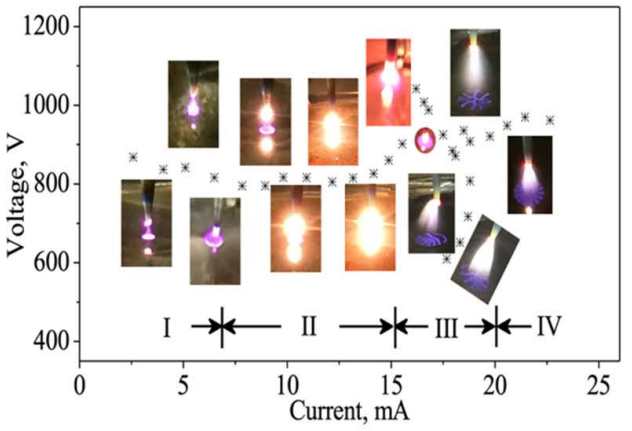

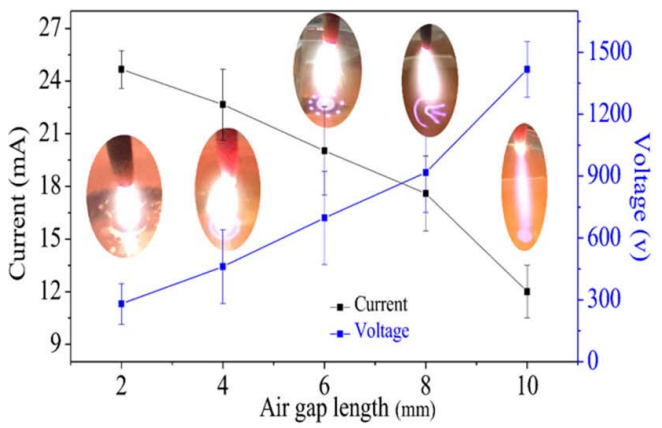

Fig. 2. Effect of experimental setups and conditions on SOPs I. (a) Experimental setup (left) and the current-voltage characteristics affecting SOPs are divided into four stages (right) (reproduced from [24]). (b) Experimental setup (left) and air-gap lengths affect SOPs using SS anode (right) (reproduced from [25]).

conductivity play important roles in generating SOPs in glow discharge [40]. Miao et al. [18] and Wilson et al. [19] have indicated that there was a small circular shape on the anode spot when the discharge current was $10 \mathrm{~mA}$. When the current increase from 15 to $25 \mathrm{~mA}$, the anode spot became a ringlike structure. The near anode plasma self-organization will be observed with further increasing the discharge current.

Fig. 2(b) shows the effect of gap lengths on atmospheric glow discharge on liquids electrodes. Different air gap lengths (2-10 $\mathrm{mm})$ between SS anode and a metal pin cathode were considered for studying SOP at the liquid surface. The stable SOP can be observed at the liquid interface at a 6-mm air-gap length. The discharge pattern with low voltage and high current represents a single filament at a $2-\mathrm{mm}$ gap. The anode spot turns into a double ring-like structure at a 4-mm air gap length. Different types of SOPs appear above the liquid media surface at 8-mm air gap length. Similarly, Verreycken et al. [39] reported SOPs observed with the electrode separation of $5 \mathrm{~mm}$. Given these results, the SOPs of the liquid anode depend on the gap length.

SOPs at different conductivity and exposure time are shown in Fig. 3(a). Individual small spots compose the stripe patterns at larger exposure time. Radial stripes become a more homogeneous middle part with encircling stripes, when the liquid electrode's conductivity increases. These authors also show a descending trend in voltage with an increasing conductivity. Due to voltage decreasing with increasing conductivity, plasma temperature drops with decreasing current [17]. In addition, liquid types also affect SOPs due to their different conductivity and the negative ions resulting from electron affinity [41]. Fig. 3(b) shows the effect of gas type on SOPs formation.
The anode SOPs are observed in air sheath flow, not in $\mathrm{N}_{2}$ sheath flow. Different patterns are observed in $\mathrm{O}_{2}$ sheath flow, and the patterns randomly change. Thus, $\mathrm{O}_{2}$ sheath flow highly affects the anode pattern structure. On the other hand, the ringlike structure in air and $\mathrm{N}_{2}$ mixture (not in pure $\mathrm{N}_{2}$ or $\mathrm{He}$ ) was observed by Wilson et al. [19]. Given the above results, the appearance of the SOP on the anode surface might depend on the gases. The authors also mentioned that the pattern formation depended on the electrolyte's temperature, namely, the amount of electrolyte vapor (consisting of electronegative gases) in the gas in the gap [42], [43]. Electronegative gases usually capture free electrons and generate negative ions in a discharge, which might cause changing the number of electrons near the liquid electrode surface. In a liquid electrode (such as water or SS) discharge process, the gas [such as hydrogen $\left(\mathrm{H}_{2}\right)$, chlorine $\left(\mathrm{Cl}_{2}\right)$ or oxygen $\left(\mathrm{O}_{2}\right)$ ] will appear at the liquid surface owning to the electrolysis [44], [45]. Although the mechanism of pattern formation affected the gas is not yet completely understood, the $\mathrm{O}_{2}$ existence definitely influences the anode pattern. The effect of $\mathrm{pH}$ on SOPs is shown in Fig. 3(c). Plasma induces changes on an electrolyte anode by the change in $\mathrm{pH}$. The results indicate decreasing $\mathrm{pH}$ with the types of patterns formed: rings, double-rings, or spots. Thus, the continuous operation of the plasma, decreasing the liquid $\mathrm{pH}$ values, and increasing electrolyte conductivity, results in increasingly constricted anode SOPs.

\section{Theoretical Modeling of Self-Organization In Plasma Discharges}

From a theoretical point of view, nonlinear chemical dynamics combined with kinetically appropriate feedback loops 

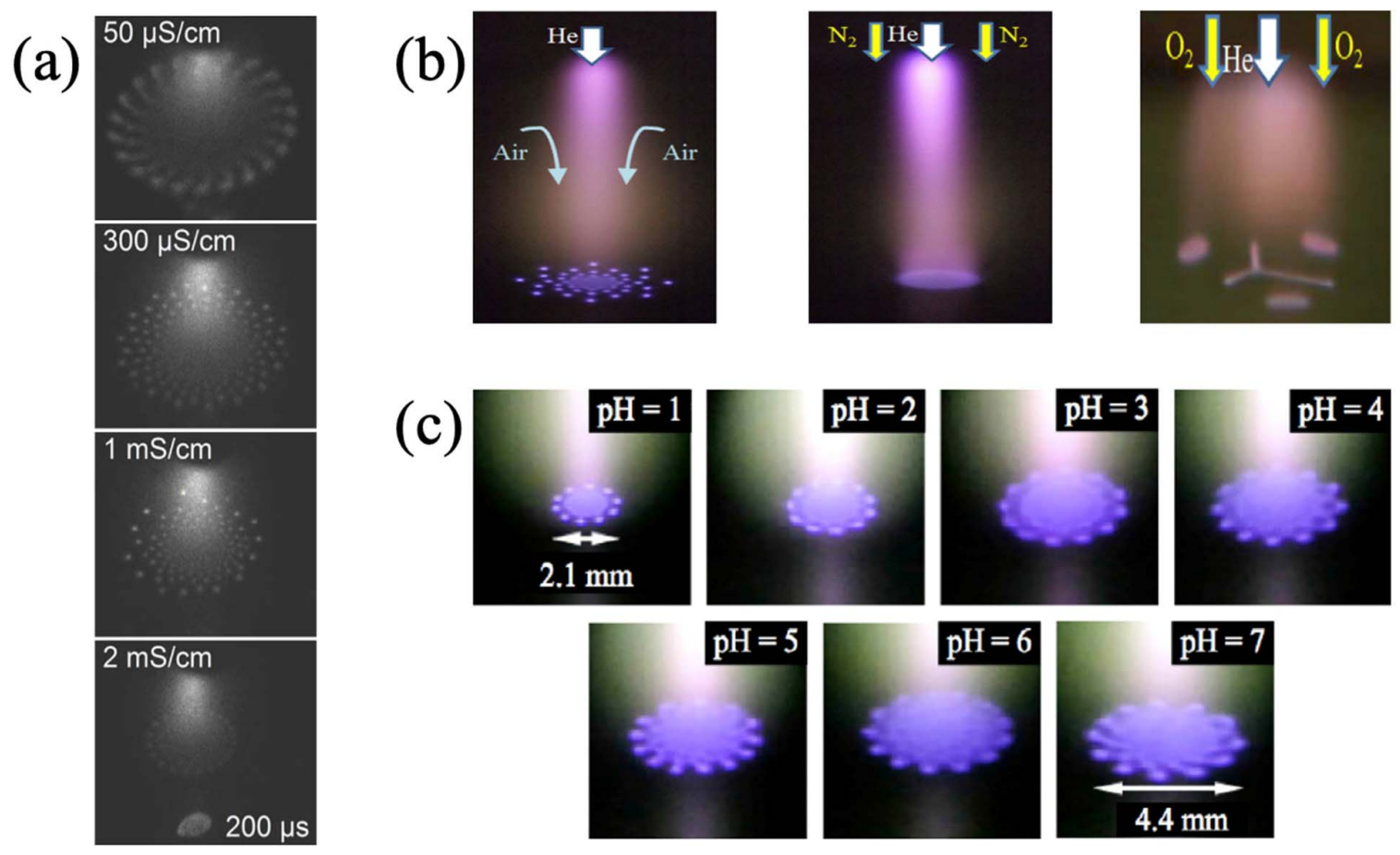

Fig. 3. Effect of experimental conditions on SOPs II. (a) Anode patterns with different conductivities at 70-mA and 200- $\mu$ s exposure time (reproduced from [39]). (b) Effect of the gas species around the discharge on SOP: air (helium flows through ambient air, and exposure time for the photographs is 1/30 s), $\mathrm{N}_{2}$ (sheath flow of $1000 \mathrm{sccm}$, and exposure time for the photographs is $1 / 30 \mathrm{~s}$ ), and $\mathrm{O}_{2}$ (sheath flow of $1000 \mathrm{sccm}$, and exposure time for the photographs is $1 / 500 \mathrm{~s}$ ) (reproduced from [46]). (c) Variation patterns as a function of electrolyte $\mathrm{pH}$ (at a 6-mm interelectrode gap and 7-kHz frequency) (reproduced from [47]).

(transport phenomena, for instance) in an irreversible process can lead to SOPs. The SOP in plasma is also an example among such universally observed phenomenon. Physically, plasma is described as a compressible, reactive, and electromagnetic fluid [3], [48]. In plasma discharge processes, plasma is assumed to be in equilibrium chemically but in nonequilibrium thermodynamically in the presence of large field gradients. Essentially, the plasma discharge processes are inherently a multiscale phenomenon with multiphysics involved which make numerical simulation a severe challenging task. With the atomistic details and quantum mechanical effects being neglected, the plasma is conventionally modeled at the continuum level with a set of assumptions to simplify the real-world problems. Of particular relevance for the modeling are drift-diffusion models and nonequilibrium plasma flow models [4]. In the following, we will be mainly concerned with computational studies of SOPs in: 1) plasma flow model and 2) multiple solutions in cathodes of glow and arc discharges.

In addition to the fluid description in chemical equilibrium and thermodynamic nonequilibrium, the plasma model is based on the following assumptions [48], [51]: 1) the plasma is a nonmagnetized, nonrelativistic, and quasi-neutral fluid; 2) neglect ion diffusion and Hall currents; and 3) the plasma is optically thin. To adequately describe time-dependent, thermodynamic nonequilibrium discharge process and formation of SOPs, the proposed plasma discharge models need to include: 1) a fluid flow model; 2) an electromagnetic field evolution model; and 3) material properties based constitutive model. More specifically, the fluid model consists of a set of transientadvective-diffusive-reactive (TADR) transport equations to describe the conservation law of total mass, mass-average linear momentum, and thermal energy of heavy species and electrons. Based on the assumption that the plasma fluid is nonrelativistic, nonmagnetic, and quasi-neutral, macroscopic Maxwell's equations can describe the electromagnetic field evolution [52], [53]. The final six of fluid-electromagnetic equations with the form "Transient + Advective - Diffusive Reactive $=0$ " is summarized in Table I [48]. It should be noted that such a format has an advantage in the formulation of the numerical solver.

Benilov and collaborators have published series papers on multiple solutions in thermionic cathodes [49], [50], [54], [55]. Generally speaking, their approach follows the treatment of self-organization in the systematic framework of bistable nonlinear dissipative systems with computational stability/bifurcation analysis. It was pointed out that in numerical modeling of transport in cathodes of DC glow and arc discharges, bifurcations need to be properly analyzed in order to better understand numerical results and the essential physics. Two key points should be stressed in their approach: 1) given the same discharge current, multiple solutions should exist in the self-consistent theoretical models so that a spotless mode and modes with patterns can be captured and 2) strong positive feedback is required. It represents the characteristic feature of the bistable system. The near-cathode space-charge sheath (sometimes referred to cathode sheath instability) as a basic mechanism can fulfill the criterion.

Pattern formation is generally found in processes over electrodes, including parallel plates and thin slits. SOPs at electrodes are distinctly different at the anodes and the cathodes. 
TABLE I

Equations Comprising the Nonequilibrium Thermodynamic Arc Discharge Model (Reproduced From [48])

\begin{tabular}{lccccc}
\hline Equation & Var. Transient & Advective & Diffusive & Reactive \\
\hline (E1) Total mass & $p$ & $\partial_{t} \rho$ & $\mathbf{u} \cdot \nabla \rho+\rho \nabla \cdot \mathbf{u}$ & 0 & 0 \\
(E2) Momentum & $\mathbf{u}$ & $\rho \partial_{t} \mathbf{u}$ & $\rho \mathbf{u} \cdot \nabla \mathbf{u}+\nabla p$ & $\nabla \cdot \mu\left(\nabla \mathbf{u}+\nabla \mathbf{u}^{T}-\frac{2}{3}(\nabla \cdot \mathbf{u}) \mathbf{6}\right)$ & $\mathbf{J}_{q} \times \mathbf{B}$ \\
(E3) Energy heavy-species & $T h$ & $\rho \partial_{t} h_{h}$ & $\rho \mathbf{u} \cdot \nabla h_{h}$ & $\nabla \cdot\left(\kappa_{h} \nabla T_{h}-\sum_{s \neq e} h_{s} \mathbf{J}_{s}\right)$ & $D_{t} p_{h}+K_{e h}\left(T_{e}-T_{h}\right)-\boldsymbol{\tau}: \nabla \mathbf{u}$ \\
(E4) Energy electrons & $T e$ & $\rho \partial_{t} h_{e}$ & $\rho \mathbf{u} \cdot \nabla h_{e}$ & $\nabla \cdot\left(\kappa_{e} \nabla T_{e}-h_{e} \mathbf{J}_{e}\right)$ & $D_{t} p_{e}-K_{e h}\left(T_{e}-T_{h}\right)+\mathbf{J}_{q} \cdot(\mathbf{E}+\mathbf{u} \times \mathbf{B})-4 \pi \varepsilon_{r}$ \\
(E5) Charge conservation & $\phi_{p}$ & 0 & 0 & $\nabla \cdot \sigma\left(\nabla \phi_{p}-\mathbf{u} \times \nabla \times \mathbf{A}\right)$ & 0 \\
(E6) Magnetic induction & $\mathbf{A}$ & $\partial_{t} \mathbf{A}$ & $\nabla \phi_{p}-\mathbf{u} \times \nabla \times \mathbf{A}$ & $\left(\mu_{0} \sigma\right)^{-1} \nabla^{2} \mathbf{A}$ & $\mathbf{0}$ \\
\hline
\end{tabular}

(a)

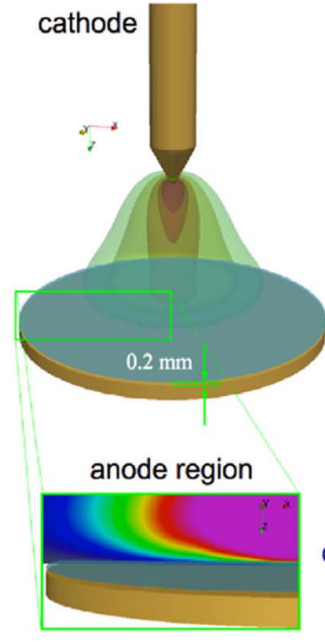

(b)

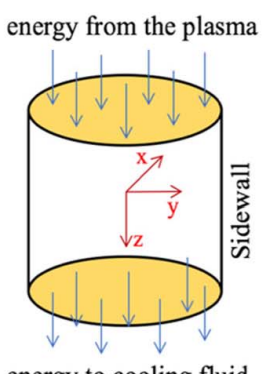

energy to cooling fluid

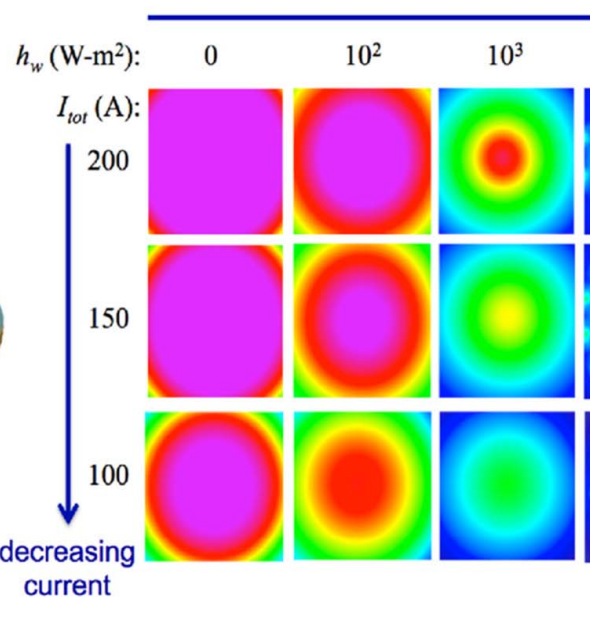

$2 \mathrm{D}$

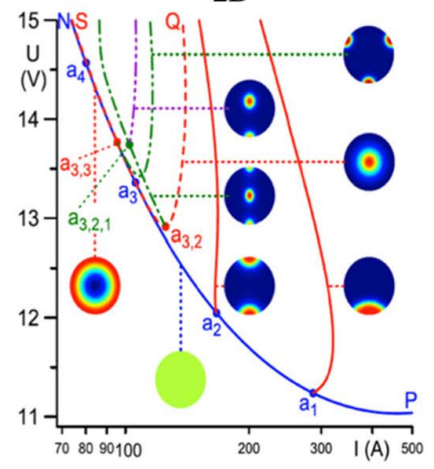

increasing cooling

$10^{4} \quad 10^{5}$

$\infty$

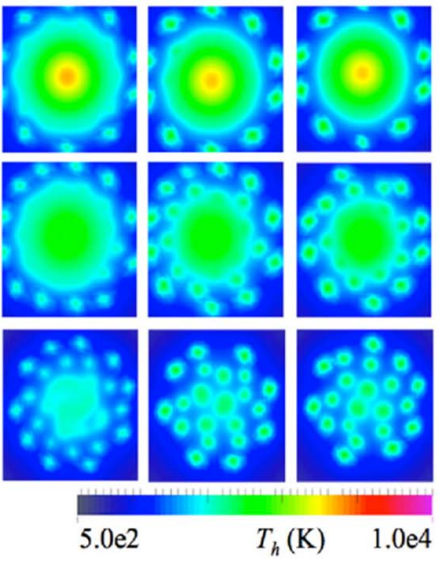

$3 \mathrm{D}$

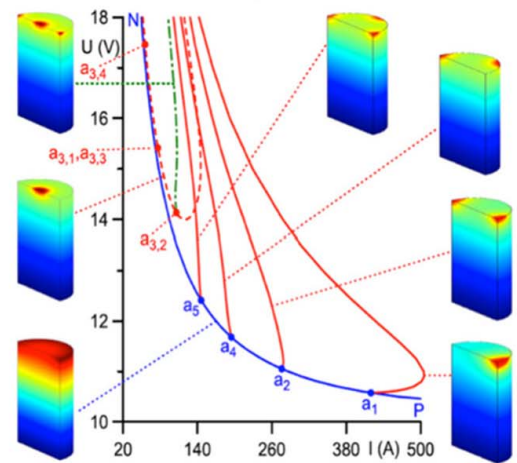

Fig. 4. (a) Anode patterns in the free-burning arc: isosurfaces depicting the 3-D solution (left-top), close-up of the region near the anode (left-bottom), and the effect of total current and degree of anode cooling on anode patterns (right) (reproduced from [4]). (b) Solutions in cathodic arc discharges: schematic of the model, 2-D solutions, and 3-D solutions (reproduced from [49] and [50]).

Fig. 4 shows the simulation results of the anode pattern by FEM in the free burning arc by solving the plasma flow model and multiple solutions in cathodic arc discharges with stability/bifurcation analysis. Fig. 4(a) shows the effect of the total current and degree of anode cooling on SOP in the freeburning arc. Left-top of Fig. 4(a) shows that the arc 3-D view is given by isosurfaces of heavy species temperature, while the left-bottom of Fig. 4(a) depicts the region near the plane and the anode where the SOPs are extracted. The results elucidate that there is a major attachment spot in the middle of the small attachment spots at higher total current and cooling degree.
When the total current is $200 \mathrm{~A}$, the anode pattern transition from axisymmetric diffuse to a dominant central spot pattern with surrounding with a set of smaller spots/planetary. With the increase of cooling, the pattern becomes more accentuated. The transition associated with a bifurcation event occurs for a value of $h_{w} \sim 10^{3}-10^{4} \mathrm{~W} \cdot \mathrm{m}^{-2} \cdot \mathrm{K}^{-1}$. This range of $h_{w}$ is discovered for the total current 100 and $150 \mathrm{~A}$ in the transitions. However, the SOPs evolve from planetary and axisymmetric to asymmetrical at $150 \mathrm{~A}$ with an increasing $h_{w}$. Moreover, the patterns appear small spots in an asymmetric arrangement of for $100 \mathrm{~A}$ and high cooling levels. These 
computational results show that anode spots initiate at the arc fringes, which agree with conclusions reported by Yang and Heberlein [56] from experimental observations and stability analyses.

Fig. 4(b) represents the multiple steady-state solutions of plasma-cathode interaction in cathodic arc discharges in the geometric setup shown on the left. This idealized geometry admits 1-D current density-voltage characteristic (CDVC) solution marked by a blue NP line (middle panel for 2-D). With an account of the effect of the lateral wall, the blue NP line represents the fundamental-mode solution (right panel for 3-D). They both correspond to the uniform solution (also called spotless mode), which is considered as the cold arc portion [57]. Typical representations of current density distribution over the cathode surface (2-D) and over the surface of a cylindrical arc cathode (3-D) associated with each solution are illustrated, indicating the richness of phenomenological aspects in processes of pattern formation over arc discharge cathodes. It should be noted that the 2-D solutions and 3-D solutions are obtained by a zero-gradient boundary condition over the sidewall boundary and allowing heat conduction through the sidewall, respectively. Multidimensional solutions of the $n$ generation branching off from the $n-1$ dimensional solutions at different bifurcation points are also shown. These results demonstrate that stability/bifurcation analysis helps us better understand the distinct features of patterns of steadystate modes and their stability. These cathode models can be applied to the melting/evaporation of cathode material, which may affect the SOPs. The simulation investigations agree with the experimental observation and indicate that evaporation of cathode induces increasing electrical conductivity in anode region [58]. The above computational investigations of new solutions have proved relevant for industrial applications and could be employed to assist cathode design.

\section{SOP PlASMA-ACTIVATED LIQUIDS}

SOP plasma is one type of cold atmospheric plasma (CAP). The difference for common plasma-activated medium (PAM) from the PAM with SOPs is that SOPs form at the interface. The special difference may be that SOP plasma is capable of efficiently controlling the ROS/RNS concentrations in the therapeutical media, and in particular, the ROS/RNS ratios not achievable by other types of discharges could be obtained [24]. The efficiency of plasma-activated liquid or plasma on agricultural and biomedical applications depends on ROS/RNS generation [41], [60]-[63]. Many ways have been devised to detect free radicals and their derived oxidants with different levels of accuracy and sensitivity [64]. These include chemiluminescent assays, chemical assays, fluorescence detection, chemiluminigenic probes, electron paramagnetic resonance (EPR) spectroscopy, and colorimetric (Griess reaction) and related methods [65]-[69]. EPR spectroscopy can directly detect reactive species, while other assays enable being informative if employed with proper controls. The effect of SOP plasma-activated liquids on plants or other biological objects, microbial, viral, and cancer cells is in the same way as plasma-activated liquids with any patterns. Different
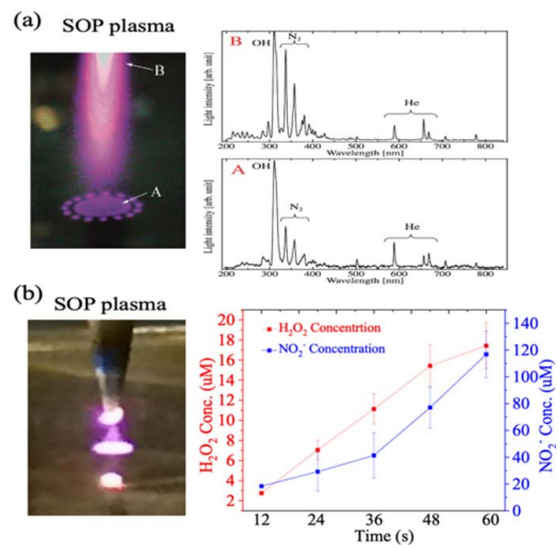

Fig. 5. (a) SOPs appeared on the electrolyte anode surface and OES from $1 \% \mathrm{Na}_{2} \mathrm{SO}_{4}$ solution anode (reproduced from [59]). (b) Image of the SOPs above the DI water: $\mathrm{H}_{2} \mathrm{O}_{2}$ and $\mathrm{NO}_{2}^{-}$concentration of in liquid after SOP plasma treatment with different time (reproduced from [24]).

plasma devices are able to generate SOPs, including pin-water glow discharge setups, gas feeding microdischarge devices, and DBD-like devices [39], [70], [71]. Fig. 5(a) shows the spectrum distribution of SOPs using the $1 \% \mathrm{Na}_{2} \mathrm{SO}_{4}$ solution. The radial distribution of nitrogen lines intensities had a diffused shape involving that for the He atomic line, peaking at the nozzle axis. The anode spot region emission is the same as that of the $\mathrm{PC}$. $\mathrm{OH}$ emission and $\mathrm{N}_{2}$ second-positive system $\left(C^{3} \Pi_{u}-B^{3} \Pi_{g}\right)$ are mainly emissions. NO lines are weak emission bands in the 250-300 $\mathrm{nm}$ wavelength range [72]. The range of 500 and $750 \mathrm{~nm}$ is detected as helium bands. ROS/RNS could be defined between 250- and 425-nm bands. Shirai et al. [42] indicate that a difference appears in the NG region spectra when the electrolyte was the cathode.

Plasma-activated water (PAW) can be obtained in two modes: plasma discharge above the water surface and plasma discharge in water. Plasma discharge in water has lower energy efficiency comparing with the above water surface [73]. Plasma discharges over liquid surfaces, and resulting in reactive oxygen species/reactive nitrogen species (ROS/RNS) transferring from the gas phase to the liquid [74]. For SOP plasma, plasma-treated liquids (such as PAW) are obtained from SOP plasma forming over the liquid's surface. Fig. 5(b) shows the ROS/RNS contents in the self-organization glow discharge-treated DI water. The concentration of $\mathrm{H}_{2} \mathrm{O}_{2}$ and $\mathrm{NO}_{2}^{-}$increase with the treatment time [75], [76]: possible reactions about $\mathrm{H}_{2} \mathrm{O}_{2}$ and $\mathrm{NO}_{2}^{-}$formation in plasma-treated liquid are listed in [77]. On the other hand, scientists also proposed potential chemical and physical processes taking place at the plasma-liquid interface [78], as shown in Fig. 6. These processes contain gas multiphase species transport, phase chemistry, interfacial reactions, mass and heat transfer, and liquid phase chemistry. At the plasma-liquid interface, temperature gradients are characterized, and it still needs to determine whether a real connection between plasma at liquid water and a supercritical temperature occurs. There is a distinction between the interfacial region and the bulk liquid. The interfacial region is the location related to the major processes of short-lived species occurring. Some reactive species, such as $\mathrm{O}$ atoms, $\mathrm{OH}$ radicals, and $\mathrm{OOH}$ radicals, penetrate the 


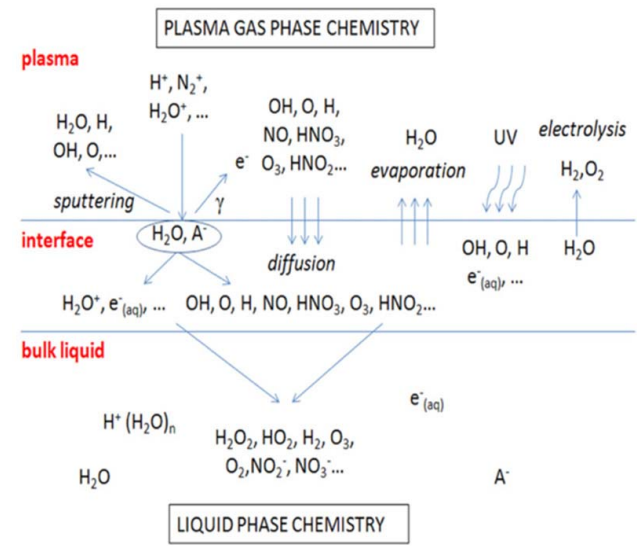

Fig. 6. Important processes of reactive species transferring at the plasma-liquid interface (reproduced from [82]).

interfacial region into the bulk liquid and interact with it [79], [80]. The interfacial layer thickness will change because radicals have different depths of penetration based on their lifetimes. Finally, plasma species into liquids become plasma solutions including ROS/RNS [81]. Generally, ROS/RNS plays a major role in plasma agriculture, food safety, and plasma medicine, such as replacing the traditional sanitizing solution applied for disinfection, applying for seeds/crops as fertilizer, and using as an anticancer, antimicrobial, and dental treatment agent. We will discuss the potential applications of SOP plasma activating liquids for agriculture, food safety, and biomedicine in the following next two sections.

\section{Potential Agricultural Applications of SOP PLASMA-ACTIVATED LIQUIDS}

According to the State of Food Security and Nutrition in the World 2019, world hunger has slowly been on the rise since 2015 after decades of steady decline. There are approximately 821 million people suffering from hunger around the world in 2018. By 2050, the population will reach 10 billion on earth, which urgently requires innovative approaches for agriculture and food production. It highly challenges to produce lots of foods with safety and high quality during food production due to emerging pathogens. Cold plasma has great potential in several applications of food industry: microbial disinfection, starch modification, improving rice cooking quality, enzymatic inactivation, and enhancing germination of seed [83]-[85]. For example, enzymes like peroxidases and polyphenol oxidases involving enzymatic browning reactions induce the loss of nutritional quality, while enzymes like lipoxygenase, lipases, and pectin methylesterase result into a detrimental effect on the food organoleptic quality [86], [87]. Plasma-treated liquid has the ability to kill a large panel of germs and deactivate microorganisms that otherwise cannot be disinfected by gas plasma [88], [89]. SOP plasma-treated liquids, containing mainly ROS and RNS, can be an alternative method for sterilization of foods and fertilizers for crops and seeds.

Fig. 7(a) illustrates the effect of PAW on the development of the root system of Zinnia annual spears. The groundwater treated by plasma yields a $15 \%-20 \%$ increase of the degree
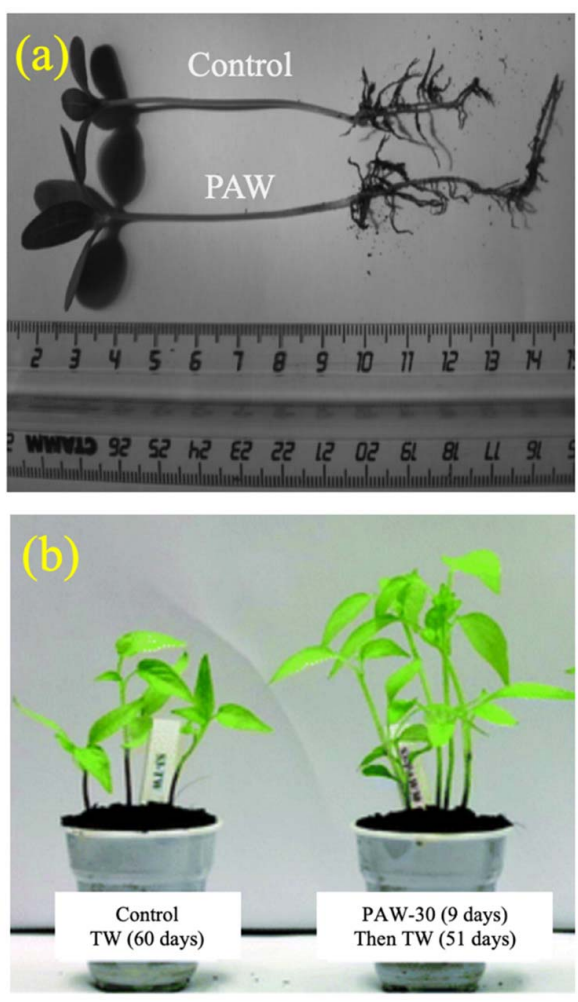

Fig. 7. (a) Effect of PAW on the development of the root system of Zinnia annual spears (reproduced from [103]). (b) Long-term effect of PAW on pepper crops. PAW-30: DI water treated by plasma for $30 \mathrm{~min}$ and TW: tap water (reproduced from [96]).

of the culture's germinability and a 1.5- to 2-fold increase in the plant roots' length comparing with the control specimens. PAW-treated seeds increase eventual yield, which could be partially (at least) involving antimicrobial and antifungal [90]. It has to clear up the role of the biological factors and surface chemistry in enhancing the yield: the permeability of $\mathrm{O}_{2}$ and $\mathrm{CO}_{2}$ in PAW is essential for germination [91]-[93]. PAW can be used as a potential method for pretreatment of seeds to increase yield and control the germination speed. PAW-treated seeds with high hydrophilicity might save a lot of water necessary for irrigation [94], [95]. Fig. 7(b) shows the effect of PAW on pepper plant growth and healthier leaves. The efficiency of seeds germination depends on the PAW treatment time, that is the amount of hydrogen peroxide $\left(\mathrm{H}_{2} \mathrm{O}_{2}\right)$ and nitrate $\left(\mathrm{NO}_{3}^{-}\right)$produced in the water [96]. Also, the retention of seeds nutritional characteristics is important, and reactive species in PAW can cause important changes in grains' physicochemical constituents. Applying PAW to the food and agriculture has the potential to increase food quality and safety [97], [98]. It can efficiently degrade pesticides/mycotoxins, reduce food waste, and inactivate pests, which also can be used to generate nitrate-rich substrates as fertilizer [60], [99]. In PAW treatment process, lipid/starch oxidation and protein modification can occur through multiple chemical reactions [100]. Lots of DBD reactors are utilized for the treatment of liquids: the plasma easily forms SOPs at the liquid interface and the radicals diffuse in depth to obtain plasma solution for agriculture and food processing [101], [102]. SOP plasma or SOP plasmatreated liquids for the food and agriculture continuum poten- 
tially increase food quality and safety, which can efficiently inactivate pests as well as degrade pesticides/mycotoxins. SOP plasma-treated liquids can be employed to produce rich substrates' nitrate, thus increasing seeds yield and germination.

The efficiency of inactivation depends on PAW treatment time [104], [105]. The PAW electrical conductivity increases linearly with the plasma treatment time, and the $\mathrm{pH}$ quickly drops in the first 10-min treatment and reached around 3 with a steady-state after 20-min treatment [106]. Many scientists also speculated that reactive species and acidity in PAW were interconnected. Lower $\mathrm{pH}$ helps ROS/RNS to penetrate cell walls, and ROS/RNS decreases the resistance of bacteria to acidic environment [107]. Active ions generating in the PAW were various ROS/RNS [108]-[111]. ROS, as the most important agents, generate in the inactivation process, which is long- and short-lived species. On the other hand, PAW containing complex chemical compounds can create other species with a lethal effect [112]. For example, the synergistic combination of $\mathrm{H}_{2} \mathrm{O}_{2}$ and $\mathrm{NO}_{3}^{-}$has an antibacterial function. Choi et al. [113] compared PAW with sodium hypochlorite and tap water (TW) on killing foodborne pathogens, inactivation of background microbiota, and shredded salted Chinese cabbages' quality. PAW shows a significant reduction in lactic acid bacteria, mesophilic aerobic bacteria, coliforms, yeast, and molds. In addition, to compare with the antibacterial efficiency of PAW, Qian et al. investigated plasma-treated lactic acid (PALA) affecting beef quality and Salmonella Enteritidis [115]. The PALA antibacterial activity is closely involving the synergistic effect of $\mathrm{H}_{2} \mathrm{O}_{2}$ and $\mathrm{NO}_{2}^{-}$, and there was no negative effect on beef quality (similar to PAW).

Fig. 8 shows the potentials mechanisms for the disinfection of PAW. The $\mathrm{pH}$ is related to the ROS/RNS and largely depends on the feed gas, treatment time, and treatment distance [114]. Most of the bacteria are significantly affected the environmental $\mathrm{pH}$ due to no mechanism to change their internal $\mathrm{pH}$. The mechanisms of UV radiations and shock waves in PAW are the thymine bases' dimerization in DNA strands and the creation of cavitation bubbles, respectively [116]. Major ROS in PAW, including $\mathrm{H}_{2} \mathrm{O}_{2}$, hydroxyl radical $\left.{ }_{*} \mathrm{OH}\right)$, and ozone $\left(\mathrm{O}_{3}\right)$, is evaluated as potent antimicrobial agents [117], [118]. The ${ }_{*} \mathrm{OH}$ starts the peroxidation reaction of lipid through subtracting $\mathrm{H}$ from the unsaturated carbon bonds of fatty acids resulting in the end product: malondialdehyde, which damages DNA and induces cell death [119], [120]. Generally, the transport of $\mathrm{H}_{2} \mathrm{O}_{2}$ and $\mathrm{O}_{3}$ from the PAW into the microbial cells induces the internal injure via the destruction of proteins, and breakdown of DNA and other internal components. One more $\mathrm{H}_{2} \mathrm{O}_{2}$ antimicrobial mechanism is to generate intracellular $* \mathrm{OH}$ causing oxidative damage of DNA [121], [122]. The major RNS in PAW, including nitrates, nitric oxide (NO), nitrites, and peroxynitrites $\left(\mathrm{ONOO}^{-}\right)$, lower the $\mathrm{pH}$ and form strong oxidizer $\left(\mathrm{ONOO}^{-}\right)$for microbial disinfection [123]. Moreover, the combination of physical parameters and RNS/ROS can have a synergistic effect. The oxidation-reduction potential also plays an important role in the microbial inactivation, damaging the cell membrane and defense mechanism [124]. Four potential mechanisms are driven by PAW treatment and

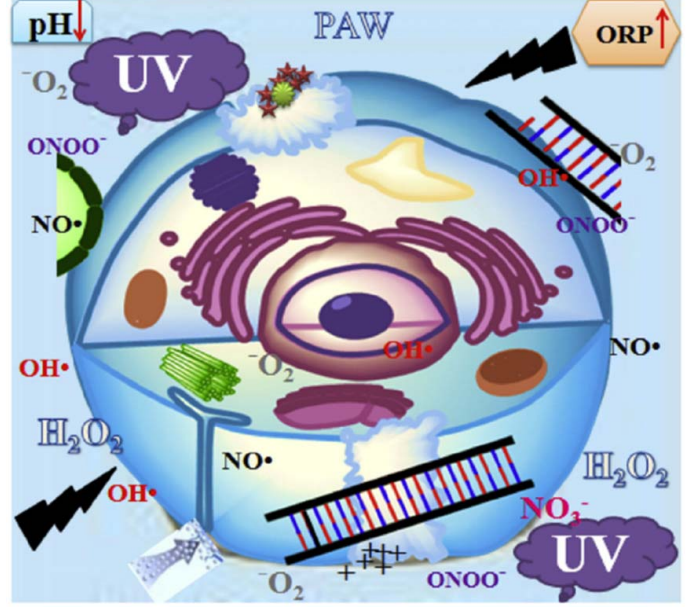

Fig. 8. Schematic of the PAW causing cell death through different mechanisms: lipid peroxidation, ROS/RNS, electroporation (+), and physical parameters (reproduced from [125]).

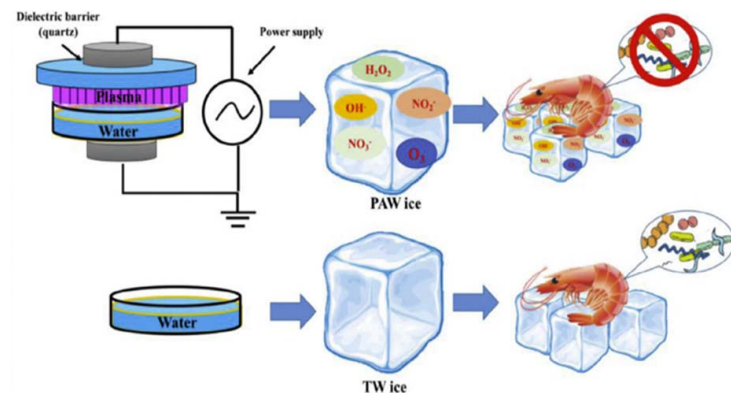

Fig. 9. Application of PAW (generated by DBD) ice for shrimp preservation (reproduced from [130]).

contribute to bacterial cell death, containing damaging cell membranes, etching cell walls, destruction of genetic material, and protein/enzyme denaturation.

Seafood, rich in lipids and proteins, has limited shelf-life and easily loses its quality due to the activity of spoilage microbes and endogenous enzymes [126]. PAW ice provides an alternative storage technology for the food industry. Fig. 9 shows the application of PAW (generated by DBD) ice for storage of shrimps, and PAW ice efficiently inhibit the microorganism growth, and stops losing freshness shrimp and quality, inducing longer shelf life. Aspergillus spp. are generally considered as "storage" contaminants and their growth is involving inefficient drying [127]. The overall effects of PAW on Aspergillus spp. significantly decrease the remaining counts and subsequently induce cell leakage. Meanwhile, Ma et al. [128] demonstrated that PAW could kill S. aureus inoculated on strawberries without causing a significant change in $\mathrm{pH}$, firmness, and color. During six-day storage after PAW treatment, there is almost no visual fungal spoilage on the strawberries. Cebrián et al. [129] also proposed that S. aureus developed stress resistance responses after exposure to sublethal environmental stress, inducing homologous stress resistance increased via causing a program of protein synthesis and gene expression.

Plasma-treated buffer, containing ROS and RNS, is an effective and safe antimicrobial agent against pathogenic bacteria of 


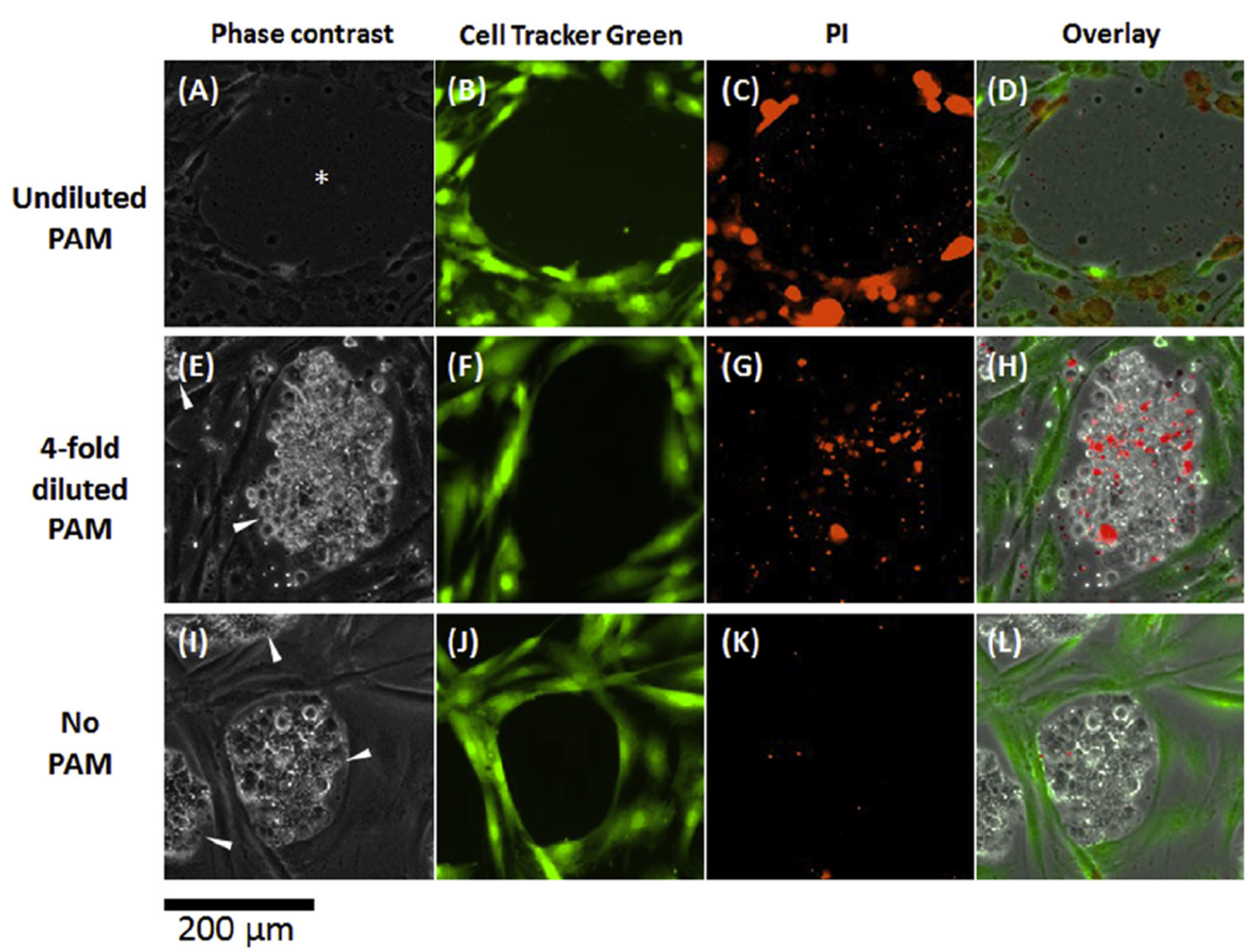

Fig. 10. Effects of PAM on differentiated cells NHDFs and undifferentiated 201B7 hiPSCs. Cells treated with (A)-(D) undiluted PAM, (E)-(H) fourfold diluted PAM, and (I)-(L) without PAM. (A) Asterisk indicates the hiPSCs attachment before PAM treatment. (E) and (I) Arrowheads indicate hiPSCs (reproduced from [147]).

plant and has a wide range of applications to enhance the shelf life of stored food and crop production [131]. Chen et al. [132] studied the effects of PAW on antioxidant activity, quality maintenance, and the native microflora survival of fresh-cut pears, indicating that PAW highly prohibited the growth of aerobic bacteria, mold, and yeast during storage. There is no significant change in the titratable acidy and soluble solid content. Gavahian et al. [133] investigated PAW affecting visual quality and the textural of shiitake mushrooms. After stored for 1 week, PAW treatment enhances the postharvest quality and limits textural changes and undesirable color. Thus, the above results provide significant insight into developing and applying PAW to improve the quality of products and microbiological safety in the food industry. The potential applications of PAW in agriculture and food are extensive, including sterilization of seeds, enhancing seed germination and yield, removal of volatile organic compounds, postharvest sanitation, fertilizer, reducing pathogen invasion, disinfection of products prior to packaging, control of pests and pathogens during retail storage and display, sterilization of food processing equipment, and others [134]-[138].

\section{Potential Biomedical ApPlications of SOP Plasma-ACTIVATED LiQUidS}

Cold plasma can be employed for biomedical applications because plasma is generated at room temperature and atmospheric pressure containing ROS and RNS [139], [140]. ROS and RNS promoting cell proliferation or cell death depend on the dosage. Extreme dosage of ROS induces

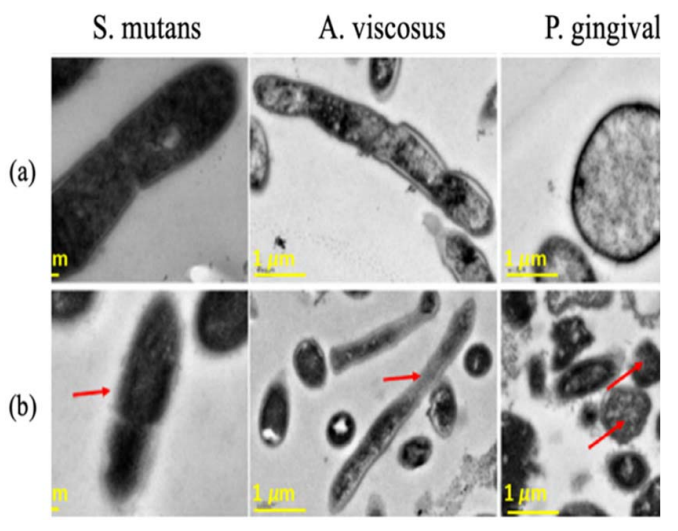

Fig. 11. TEM images of P. gingivalis, A. viscosus, and S. mutans (a) before and (b) after PAW treatment. Red arrows show the change of surface morphology after treatment of PAW (reproduced from [157]).

damage of proteins, DNA, senescence, lipids, and induce apoptosis [141], [142]. Recently, the plasma-treated liquid is one of the important plasma medicine tools and has been widely investigated for many biomedical applications, such as cancer therapy, microbial disinfection, regenerative medicine, and dental treatment [143]. Plasma-treated liquid, stable at room temperature, is unique because it can generate ROS/RNS inside tissues without harming healthy tissue. There are many factors affecting the efficacy of plasma-treated liquid, such as treatment time, storage duration, air gap, power, and storage temperature. A discussion of plasma-treated liquid for regenerative medicine, microbial disinfection, dental, and cancer therapy as follows. 
Human-induced pluripotent stem cell (hiPSCs), as one of the human pluripotent stem cells, is potential sources for cell transplantation therapy, drug screening, and regenerative medicine [144], [145]. Japanese RIKEN Center performed the first human trial of hiPSCs-derived retinal pigment epithelium in 2014 [146]. Matsumoto et al. [147] investigated PAM on hiPSCs and indicated PAM selectively killing hiPSCs and no toxic effects on differentiated cells (Fig. 10). Till now, studies characterized PAM affecting differentiated normal cells and indicated that less harmful effects were exerted by PAM on these cells. PAM has some following advantages [148], [149]: 1) easy and cheap to use; 2) elimination ability; and 3) no or minimal antigenicity. Tanaka et al. [150] showed the effect of PAM on normal astrocytes and glioblastoma cells, and pointed out that glioblastoma cells were killed by PAM via PI3K/PTEN pathway without damage of normal astrocytes. Torii et al. [151] showed similar results that gastric cancer cells are less resistant to PAM than WI-38 human fibroblasts. PAM can be clinically applied for regenerative medicine to eliminate potentially tumorigenic undifferentiated hiPSCs from a number of differentiated cells before transplantation.

Plasma-treated liquids are also employed as antiviral and medical disinfectants. Disinfection of hazardous microorganisms is unusually impotent for environmental safety, which is an important topic for public health and the economy. Zhang et al. [152] explored the sterilization efficiency of PAW against $S$. aureus. PAW treatments reduced $S$. aureus, and its sterilization efficacy depended on the concentration and treatment time. The integrity of membrane potential, cell membrane, and DNA structure, and intracellular $\mathrm{pH}$ homeostasis were damaged. Newcastle disease is an infectious viral disease and induces serious economic losses to poultry industries and domestic animals, which also has mild effects on humans [153]. Su et al. [154] studied the effect of plasma-treated solutions on the Newcastle disease virus. The possible mechanism of plasma-treated solutions' inactivation of Newcastle virus is ROS/RNS. ROS/RNS might degrade viral protein, destroy RNA structure, and change viral morphology, finally inducing virus inactivation [155]. The plasma-treated liquid is a promising environmentally friendly and chemical-free disinfectant for medical and industrial applications due to resolving the issues of environmental sanitation and public health. Also, plasma-treated liquids can be employed for the sterilization of medical equipment and dental, which are very cost effective and safe. Caries and periodontal diseases are the main factors inducing tooth loss and global oral health issues according to The World Health Organization (WHO) [156]. Li et al. [157] explored the antimicrobial effect of PAW mouthwash and elucidated that the morphology of normal cells was changed by PAW treatment, as shown in Fig. 11. This suggests that PAW could be a novel mouthwash with antimicrobial functions. Ye et al. [158] also investigated PAW-treated three oral pathogens: S. mutans, $P$. gingivalis, and A. viscosus. They indicate that PAW is a novel and promising antimicrobial mouthwash to treat periodontal related diseases and dental caries.

One of the important SOP plasma-treated liquid applications is for cancer therapy [159]-[165]. Over 100 types of
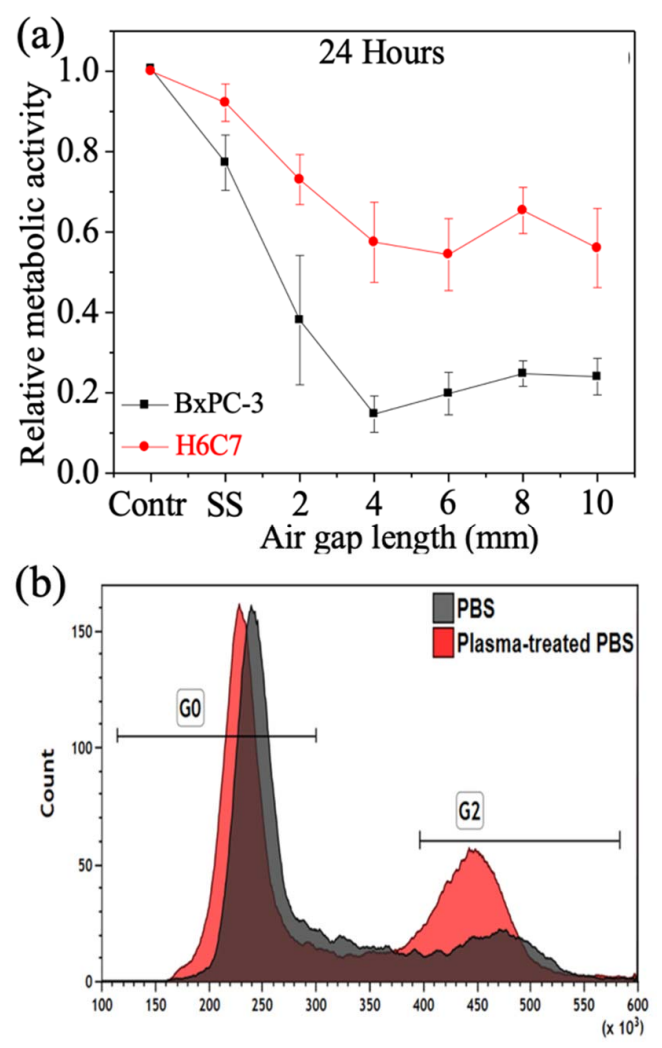

Fig. 12. (a) Effects of RPMI/KSFM, SS, and five plasma-treated SSs at 2-, 4-, 6-, 8-, and 10-mm air-gap length for 40-s duration on the viability of the H6c7 (human pancreas normal cells) and the BxPC-3 (human pancreas cancer cells) after 24-h incubation, respectively (reproduced from [25]). (b) Plasma-treated SS caused CT26 cells' morphological phenotype (reproduced from [179]).

cancers affect humans, and about 90.5 million people had cancer in 2015 [166]. Undoubtedly, cancer is a paramount important problem, thus sophisticated development approaches are urgent needs to meet these challenges. Different treatments containing medication drugs, radiation-based approaches, and surgical techniques are employed for cancer treatment. However, more progress is demanded to solve this stubborn problem and reduce drastically the mortality rate. Plasma-based cancer therapy is considered as the novel technique exhibiting a huge potential in treatment cancers [167]-[174]. Fig. 12(a) shows plasma with SOPs treating SSs employed human normal cells line H6c7 and human cancer cells line BxPC-3. SOP plasma-treating SS had an effect on the selective manner of normal and cancerous pancreatic cells. The trend of cancer and normal pancreatic cells might be related to the trend of RNS and ROS concentration. $\mathrm{H}_{2} \mathrm{O}_{2}$ reacts with $\mathrm{NO}_{2}^{-}$to form peroxynitrite $\mathrm{OONO}^{-}$and $\mathrm{H}_{2} \mathrm{O}$ [175]. $\mathrm{ONOO}^{-}$is commonly considered as a nitrating agent and powerful oxidant that damaging to cancer cells [176]. Thus, the combination of ROS and RNS in plasma solution plays a synergistic effect on apoptosis [177], [178]. Freund et al. [179] also investigated physical plasma-treated SSs employed to CT26 colon cancer cells and indicated this treatment promoted an immunogenic phenotype.

Fig. 12(b) exhibits that flow cytometry of DNA content, which shows that the amount of chromatin in the proportion of cells significantly increased twice in both groups. Cell cycle 


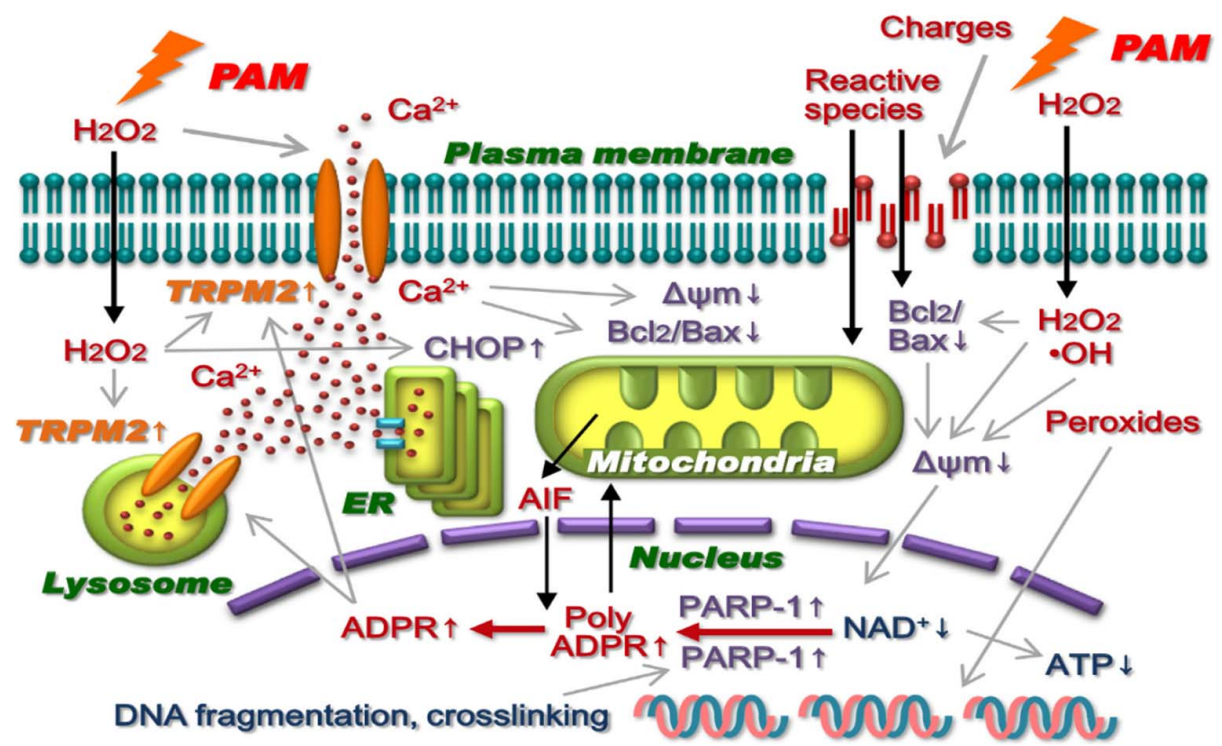

Fig. 13. Signaling mechanism for reactive species in PAM causing cell injury (reproduced from [148]).

arrest involving toxic stimuli is not special for malignant cells, generally considering as many chemotherapeutics' side effects in cancer patients [180]-[182]. Plasma-treated SS treatment leads to largely increasing calreticulin (CRT) in colon cancer cells, which is an important marker for immunogenic cell death (ICD) and the chaperon came from the endoplasmic reticulum (ER) translocating to the surface of the cell serving as an eat-me signal for tumor material phagocytosis [183]-[185]. DAMPs32 (Damage-associated molecular patterns), for example, HMGB1 (high-mobility-group-protein B1) and HSP70 (heat-shock protein 70), increased the surface of tumor cell after treatment of plasma-treated SS. Here, HSP70 is able to cause DC maturation [186]. HMGB1 is able to bind to several receptors like Tim3, RAGE, TLR4, and TLR2, and which are immunogenic signaling cascades [186]. These induce maturation of suppression of regulatory T-cells (Tregs), DC-dependent priming of T-cells, and dendritic cells (DCs) [187], [188]. Therefore, the plasma-treated SS is cytotoxic to the murine cancer cell lines PDA6606, MC38, and CT26, which raises a proimmunogenic phenotype. Tanaka et al. [189] clinically employed plasma-activated lactate (PAL) and indicated that PAL reduced tumor volumes. No side effects are noticed in the mice, suggesting PAL effective and safe. In addition, double-distilled PAW is effective to kill cancer cells, while it is suggested to employ in the clinical setting because of unfavorable osmolality. Storage of plasma-treated liquid will not lose the major oxidant $\mathrm{H}_{2} \mathrm{O}_{2}$ in the solution [190]. Numerous studies have reported cytotoxic activities of the plasma-treated cultured medium in various cancer therapy both in vitro and in vivo [33], [35], [191]-[200]. It should be pointed out that the immediate concentration of $\mathrm{H}_{2} \mathrm{O}_{2}$ in plasma-treated liquid does not depend on its protein content, indicating pretty slow decay [201]-[203]. Thus, plasma-treated saline is able to be frozen and stored for a long time, which should be further characterized for clinical cancer therapy in the future.
ROS and RNS in plasma-treated medium have been proposed for cancer therapy with a selective manner [204]. ROS is a cytotoxic agent (considered as the main mediator of plasma cytotoxicity) and inhibits cell growth at a lower concentration than commercially supplemented $\mathrm{H}_{2} \mathrm{O}_{2}$ cultures [205]-[208]. Other cytotoxic components in the plasma-treated solutions increased with plasma treatment time in line with $\mathrm{H}_{2} \mathrm{O}_{2}$ [209]. The RNS in the plasma-treated solutions has been reported to be the reason for synergistic antimicrobial effects and might also be a response to enhanced cytotoxicity [112], [210]. Reactive species in plasma increase intracellular ROS: cytokine release or cell proliferation increasing at low concentration; causing cell cycle arrest and triggering apoptosis at and higher concentration [211]-[216]. Plasma-causing apoptosis by generation of intracellular ROS is considered as the promising therapy pathway for tumor treatment, while it also brings the risks of inducing epigenetic alterations and oxidative stress-induced genetic involvement in carcinogenesis [217]-[220].

Fig. 13 shows a signaling mechanism for $\mathrm{H}_{2} \mathrm{O}_{2}$ produced by PAM-induced cell injury. ROS inducing DNA nicks' reaction activates PARP-1 and brings the cleavage of $\mathrm{NAD}^{+}$ into ADP-ribose and nicotinamide to form a number of polyADPR. It results in depletion of ATP and the consumption of NAD ${ }^{+}$. PolyADPR can mediate AIF release and translocate to the mitochondria. The AIF translocation released from the mitochondria to the nucleus triggers large-scale nuclear injury and chromatin condensation [221]. $\Delta \psi \mathrm{m}$ reduction increases the mitochondrial membrane permeabilization and allows the AIF efflux, which has been determined as a caspase-independent pathway of apoptosis [222]. $\mathrm{H}_{2} \mathrm{O}_{2}$ might disturb the mitochondrial-nuclear network through decreasing $\Delta \psi \mathrm{m}$, reducing the $\mathrm{Bcl}_{2} / \mathrm{Bax}$ expression ratio, depleting $\mathrm{NAD}^{+}$, releasing AIF, and activating PARP-1. The product of extracellular/intracellular $\mathrm{H}_{2} \mathrm{O}_{2}$ is ADPR accumulation activating TRPM2, which induces $\mathrm{Ca}_{2}^{+}$extracellular influx 
and releases from intracellular stores. Membrane damages by $\mathrm{H}_{2} \mathrm{O}_{2}$ induce apoptosis; meanwhile, it might increase membrane permeability for extracellular reactive species. Many articles have published to explain ROS-triggered apoptosis through caspase-independent pathways [150], [223]-[227]. In addition, PAM generated in a close DBD system exhibits a reduction in proliferation in the tumor model and an increase in ATP release and CRT exposure [35]. PAM shows the potential applications inducing ICD through activation of the innate immune system. PAM can be used as oral medication or injected into the blood for cancer therapy [142]. Moreover, the effectiveness of plasma-treated media/liquids increases the potential for clinical applications of cancer therapy because it can be prepared in advance and stored until use [228].

\section{CONCLUSION}

This review clearly demonstrates computational/ experimental results on the formation of the SOP in cold plasma. The computational and theoretical analysis explore more comprehensive plasma models, which are appropriate to capture the processes of SOP formation in plasma at the industrial level. There are many approaches to control SOP processes, either by suppressing or enhancing, including gas flow, gas species, gap length, electrolyte conductivity, and driving current. SOP plasma can activate various liquids, such as water, ringer's solution, SS, cultured medium, and FBS. In addition, convincing evidence of SOP plasma toward potential applications of agriculture and biomedicine has been accumulated. The fundamentals of the plasma-treated liquids properties and their actions for agricultural and biomedical applications were discussed. The ROS and RNS formation in plasma-treated liquids and their interactions cell membrane, nucleic and internal proteins are responsible for their application efficiency. It is clear that plasma-treated liquids appear to be useful, powerful, and safe tools for seed germination, plant growth, food safety, regenerative medicine, sterilization, dental diseases, cancer therapy, and plasma immunotherapy.

Although plasma-treated liquids have a number of significant advances, many questions still remain unanswered. The complexity of SOP plasma devices, such as different design and operation parameters, can produce various compounds under different mechanisms. The important limitation is the short-lived radicals generated in the plasma-treated liquids. For plasma-liquid interactions, more research related to ROS/RNS and their reactions is required to elucidate the biological effect caused by plasma-treated liquids. Scientists will pay more attention to determining the effects of plasma-treated different types of liquid solutions other than medium or water. Advanced computational methods and tools will be employed to predict chemical compounds generation or synthesis in plasma-treated liquid solutions through governing solution dilutions or reactive species. Future research will focus on investigating plasma-treated liquids' antibacterial effect on other fresh products and bacterial strains, determining foods' chemical changes and nutrition, enhancing the efficiency of inactivation, as well as developing large-scale industrial plasma device. Moreover, the safe administration routes of plasma-treated various liquids have not been established for humans yet; thus, pharmacodynamic and pharmacokinetic data are required to make plasma solution treatment more practical. In the end, more detailed research on plasma-treated liquids for a sustainable tomorrow, involving seed germination, plant growth, food safety, regenerative medicine, sterilization, dental diseases, and cancer therapy, is required to confirm their safe and potential applications.

\section{REFERENCES}

[1] Y. P. Raizer and M. S. Mokrov, "Physical mechanisms of selforganization and formation of current patterns in gas discharges of the townsend and glow types," Phys. Plasmas, vol. 20, no. 10, Oct. 2013, Art. no. 101604

[2] D. Jäger, H. Baumann, and R. Symanczyk, "Experimental observation of spatial structures due to current filament formation in silicon pin diodes," Phys. Lett. A, vol. 117, no. 3, pp. 141-144, Aug. 1986.

[3] J. P. Trelles, "Formation of self-organized anode patterns in arc discharge simulations," Plasma Sources Sci. Technol., vol. 22, no. 2, Mar. 2013, Art. no. 025017

[4] J. P. Trelles, "Pattern formation and self-organization in plasmas interacting with surfaces," J. Phys. D: Appl. Phys., vol. 49, no. 39, Oct. 2016, Art. no. 393002.

[5] H. Brandtstädter, M. Braune, I. Schebesch, and H. Engel, "Experimental study of the dynamics of spiral pairs in light-sensitive BelousovZhabotinskii media using an open-gel reactor," Chem. Phys. Lett., vol. 323, nos. 1-2, pp. 145-154, 2000.

[6] S. Kondo and T. Miura, "Reaction-diffusion model as a framework for understanding biological pattern formation," Science, vol. 329, no. 5999, pp. 1616-1620, Sep. 2010.

[7] V. Désangles, J.-L. Raimbault, A. Poyé, P. Chabert, and N. Plihon, "Pattern formation in low-pressure radio-frequency plasmas due to a transport instability," Phys. Rev. Lett., vol. 123, no. 26, Dec. 2019, Art. no. 265001.

[8] J. P. Boeuf, B. Bernecker, T. Callegari, S. Blanco, and R. Fournier, "Generation, annihilation, dynamics and self-organized patterns of filaments in dielectric barrier discharge plasmas," Appl. Phys. Lett., vol. 100, no. 24, Jun. 2012, Art. no. 244108.

[9] A. Chirokov, A. Gutsol, A. Fridman, K. Sieber, J. Grace, and K. Robinson, "Self-organization of microdischarges in dielectric barrier discharge plasma," IEEE Trans. Plasma Sci., vol. 33, no. 2, pp. 300-301, Apr. 2005.

[10] Y. Akishev, O. Goossens, T. Callebaut, C. Leys, A. Napartovich, and N. Trushkin, "The influence of electrode geometry and gas flow on corona-to-glow and glow-to-spark threshold currents in air," J. Phys. D: Appl. Phys., vol. 34, no. 18, p. 2875, 2001.

[11] M. Laroussi, I. Alexeff, J. P. Richardson, and F. F. Dyer, "The resistive barrier discharge," IEEE Trans. Plasma Sci., vol. 30, no. 1, pp. 158-159, Feb. 2002.

[12] M. Laroussi, X. Lu, and C. M. Malott, "A non-equilibrium diffuse discharge in atmospheric pressure air," Plasma Sources Sci. Technol., vol. 12 , no. 1, p. 53, 2003.

[13] K. Müller, "Structures at the electrodes of gas discharges," Phys. Rev. A, Gen. Phys., vol. 37, no. 12, p. 4836, 1988.

[14] M. Benilov, "Theory of structures in near-electrode plasma regions," Phys. Rev. A, Gen. Phys., vol. 45, no. 8, p. 5901, 1992.

[15] P. G. C. Almeida, M. S. Benilov, and M. J. Faria, "Three-dimensional modeling of self-organization in DC glow microdischarges," IEEE Trans. Plasma Sci., vol. 39, no. 11, pp. 2190-2191, Nov. 2011.

[16] L. Wang, D.-Q. Wen, Q.-Z. Zhang, Y.-H. Song, Y.-R. Zhang, and Y.-N. Wang, "Disruption of self-organized striated structure induced by secondary electron emission in capacitive oxygen discharges," Plasma Sources Sci. Technol., vol. 28, no. 5, May 2019, Art. no. 055007.

[17] P. Bruggeman, J. Liu, J. Degroote, M. G. Kong, J. Vierendeels, and C. Leys, "DC excited glow discharges in atmospheric pressure air in pin-to-water electrode systems," J. Phys. D: Appl. Phys., vol. 41, no. 21 , Nov. 2008, Art. no. 215201.

[18] S. Y. Miao, C. S. Ren, D. Z. Wang, Y. T. Zhang, B. Qi, and Y. N. Wang, "Conical DC discharge in ambient air using water as an electrode," IEEE Trans. Plasma Sci., vol. 36, no. 1, pp. 126-130, Feb. 2008. 
[19] A. Wilson, D. Staack, T. Farouk, A. Gutsol, A. Fridman, and B. Farouk, "Self-rotating DC atmospheric-pressure discharge over a water-surface electrode: Regimes of operation," Plasma Sources Sci. Technol., vol. 17, no. 4, Nov. 2008, Art. no. 045001.

[20] X. Li, P. Kang, K. Gao, S. Zhou, K. Wu, and P. Jia, "Diffuse and spotted anode layers in an atmospheric pressure glow discharge with a water electrode and miniature argon flow," Plasma Processes Polym. vol. 17, no. 7, Jul. 2020, Art. no. 1900223.

[21] A. F. Gaisin, "A vapor-air discharge between electrolytic anode and metal cathode at atmospheric pressure," High Temp., vol. 43, no. 5, pp. 680-687, Sep. 2005

[22] X. Lu and M. Laroussi, "Ignition phase and steady-state structures of a non-thermal air plasma," J. Phys. D: Appl. Phys., vol. 36, no. 6, p. 661, 2003.

[23] K. D. Weltmann, E. Kindel, T. von Woedtke, M. Hähnel, M. Stieber, and R. Brandenburg, "Atmospheric-pressure plasma sources: Prospective tools for plasma medicine," Pure Appl. Chem., vol. 82, no. 6, pp. 1223-1237, Apr. 2010.

[24] Z. Chen, S. Zhang, I. Levchenko, I. I. Beilis, and M. Keidar, "In vitro demonstration of cancer inhibiting properties from stratified selforganized plasma-liquid interface," Sci. Rep., vol. 7, no. 1, pp. 1-11, Dec. 2017.

[25] Z. Chen, L. Lin, E. Gjika, X. Cheng, J. Canady, and M. Keidar, "Selective treatment of pancreatic cancer cells by plasma-activated saline solutions," IEEE Trans. Radiat. Plasma Med. Sci., vol. 2, no. 2, pp. 116-120, Mar. 2018.

[26] R. Zhou et al., "Plasma-activated water: Generation, origin of reactive species and biological applications," J. Phys. D: Appl. Phys., vol. 53, no. 30, Jul. 2020, Art. no. 303001.

[27] E. C. Puertas, A. Dzafic, and S. Coulombe, "Investigation of the electrode erosion in pin-to-liquid discharges and its influence on reactive oxygen and nitrogen species in plasma-activated water," Plasma Chem. Plasma Process., vol. 40, no. 1, pp. 145-167, Jan. 2020.

[28] Y. Sui, Y. Dai, C. C. Liu, R. M. Sankaran, and C. A. Zorman, "A new class of low-temperature plasma-activated, inorganic salt-based particle-free inks for inkjet printing metals," Adv. Mater. Technol., vol. 4, no. 8, Aug. 2019, Art. no. 1900119.

[29] Y. Zheng et al., "Reduction of phoxim pesticide residues from grapes by atmospheric pressure non-thermal air plasma activated water," J. Hazardous Mater, vol. 377, pp. 98-105, Sep. 2019.

[30] C.-M. Lin, Y.-C. Chu, C.-P. Hsiao, J.-S. Wu, C.-W. Hsieh, and C.-Y. Hou, "The optimization of plasma-activated water treatments to inactivate salmonella enteritidis (ATCC 13076) on shell eggs," Foods, vol. 8, no. 10, p. 520, Oct. 2019.

[31] A. Bisag et al., "Plasma-activated ringer's lactate solution displays a selective cytotoxic effect on ovarian cancer cells," Cancers, vol. 12, no. 2 , p. $476,2020$.

[32] P. Lukes, E. Dolezalova, I. Sisrova, and M. Clupek, "Aqueousphase chemistry and bactericidal effects from an air discharge plasma in contact with water: Evidence for the formation of peroxynitrite through a pseudo-second-order post-discharge reaction of $\mathrm{H}_{2} \mathrm{O}_{2}$ and $\mathrm{HNO}_{2}$," Plasma Sources Sci. Technol., vol. 23, no. 1, Feb. 2014, Art. no. 015019.

[33] G. Bauer, D. Sersenová, D. B. Graves, and Z. Machala, "Cold atmospheric plasma and plasma-activated medium trigger RONSbased tumor cell apoptosis," Sci. Rep., vol. 9, no. 1, pp. 1-28, Dec. 2019.

[34] J. M. Joslin, J. R. McCall, J. P. Bzdek, D. C. Johnson, and B. M. Hybertson, "Aqueous plasma pharmacy: Preparation methods, chemistry, and therapeutic applications," Plasma Med., vol. 6, no. 2, pp. 135-177, 2016.

[35] A. Azzariti et al., "Plasma-activated medium triggers cell death and the presentation of immune activating danger signals in melanoma and pancreatic cancer cells," Sci. Rep., vol. 9, no. 1, pp. 1-13, Dec. 2019.

[36] J. Lai and J. E. Foster, "Experimental observation of interfacial oscillations and self-organization derived from streamer-driven mechanical perturbation of a gas-liquid boundary," Plasma Sources Sci. Technol., vol. 28, no. 12, Dec. 2019, Art. no. 125003.

[37] L. Dong, W. Fan, Y. He, and F. Liu, "Self-organized gas-discharge patterns in a dielectric-barrier discharge system," IEEE Trans. Plasma Sci., vol. 36, no. 4, pp. 1356-1357, Aug. 2008.

[38] L. Dong, J. Shang, Y. He, Z. Bai, L. Liu, and W. Fan, "Collective vibration of discharge current filaments in a self-organized pattern within a dielectric barrier discharge," Phys. Rev. E, Stat. Phys. Plasmas Fluids Relat. Interdiscip. Top., vol. 85, no. 6, Jun. 2012, Art. no. 066403 .
[39] T. Verreycken, P. Bruggeman, and C. Leys, "Anode pattern formation in atmospheric pressure air glow discharges with water anode," J. Appl. Phys., vol. 105, no. 8, Apr. 2009, Art. no. 083312.

[40] J. E. Foster, Y. E. Kovach, J. Lai, and M. C. Garcia, "Self-organization in 1 ATM DC glows with liquid anodes: Current understanding and potential applications," Plasma Sources Sci. Technol., vol. 29, no. 3, Mar. 2020, Art. no. 034004

[41] S. Zhang and T. Dufour, "Self-organized patterns by a DC pin liquid anode discharge in ambient air: Effect of liquid types on formation," Phys. Plasmas, vol. 25, no. 7, Jul. 2018, Art. no. 073502.

[42] N. Shirai, M. Nakazawa, S. Ibuka, and S. Ishii, "Atmospheric DC glow microplasmas using miniature gas flow and electrolyte cathode," Jpn. J. Appl. Phys., vol. 48, no. 3, Mar. 2009, Art. no. 036002

[43] N. Shirai, K. Ichinose, S. Uchida, and F. Tochikubo, "Influence of liquid temperature on the characteristics of an atmospheric DC glow discharge using a liquid electrode with a miniature helium flow," Plasma Sources Sci. Technol., vol. 20, no. 3, Jun. 2011, Art. no. 034013.

[44] M. Witzke, P. Rumbach, D. B. Go, and R. M. Sankaran, "Evidence for the electrolysis of water by atmospheric-pressure plasmas formed at the surface of aqueous solutions," J. Phys. D: Appl. Phys., vol. 45, no. 44, Nov. 2012, Art. no. 442001.

[45] N. Shirai, S. Uchida, and F. Tochikubo, "Synthesis of metal nanoparticles by dual plasma electrolysis using atmospheric DC glow discharge in contact with liquid," Jpn. J. Appl. Phys., vol. 53, no. 4, Apr. 2014, Art. no. 046202

[46] N. Shirai, S. Uchida, and F. Tochikubo, "Influence of oxygen gas on characteristics of self-organized luminous pattern formation observed in an atmospheric DC glow discharge using a liquid electrode," Plasma Sources Sci. Technol., vol. 23, no. 5, Sep. 2014, Art. no. 054010.

[47] P. Zheng et al., "Self-organized pattern formation of an atmosphericpressure, AC glow discharge with an electrolyte electrode," Plasma Sources Sci. Technol., vol. 24, no. 1, Dec. 2014, Art. no. 015010.

[48] J. P. Trelles, "Finite element methods for arc discharge simulation," Plasma Processes Polym., vol. 14, nos. 1-2, Jan. 2017, Art. no. 1600092.

[49] P. G. C. Almeida, M. S. Benilov, M. D. Cunha, and M. J. Faria, "Analysing bifurcations encountered in numerical modelling of current transfer to cathodes of DC glow and arc discharges," J. Phys. D: Appl. Phys., vol. 42, no. 19, Oct. 2009, Art. no. 194010.

[50] M. S. Benilov, "Understanding and modelling plasma-electrode interaction in high-pressure arc discharges: A review," J. Phys. D: Appl. Phys., vol. 41, no. 14, Jul. 2008, Art. no. 144001.

[51] M. S. Benilov, "Multiple solutions in the theory of DC glow discharges and cathodic part of arc discharges. Application of these solutions to the modeling of cathode spots and patterns: A review," Plasma Sources Sci. Technol., vol. 23, no. 5, Sep. 2014, Art. no. 054019.

[52] R. S. Islamov, "Physical model of anode glow patterns in elevatedpressure gas discharges," Phys. Rev. E, Stat. Phys. Plasmas Fluids Relat. Interdiscip. Top., vol. 64, no. 4, Sep. 2001, Art. no. 046405.

[53] J. P. Appleton and K. N. C. Bray, "The conservation equations for a non-equilibrium plasma," J. Fluid Mech., vol. 20, no. 4, pp. 659-672, Dec. 1964

[54] M. Benilov, M. Carpaij, and M. Cunha, "3D modelling of heating of thermionic cathodes by high-pressure arc plasmas," J. Phys. D: Appl. Phys., vol. 39, no. 10, p. 2124, 2006.

[55] M. S. Benilov, M. D. Cunha, and M. J. Faria, "Simulating different modes of current transfer to thermionic cathodes in a wide range of conditions," J. Phys. D: Appl. Phys., vol. 42, no. 14, Jul. 2009, Art. no. 145205

[56] G. Yang and J. Heberlein, "Instabilities in the anode region of atmospheric pressure arc plasmas," Plasma Sources Sci. Technol., vol. 16, no. 4, p. 765, 2007.

[57] M. Mitchner and C. H. Kruger, Jr., Partially Ionized Gases. New York, NY, USA: Wiley, 1973.

[58] K. Etemadi, G. Zhao, and J. Mostaghimi, "Impact of cathode evaporation on a free-burning arc," J. Phys. D: Appl. Phys., vol. 22, no. 11, p. $1692,1989$.

[59] N. Shirai, S. Ibuka, and S. Ishii, "Self-organization pattern in the anode spot of an atmospheric glow microdischarge using an electrolyte anode and axial miniature helium flow," Appl. Phys. Exp., vol. 2, Mar. 2009, Art. no. 036001

[60] S. Zhang, A. Rousseau, and T. Dufour, "Promoting lentil germination and stem growth by plasma activated tap water, demineralized water and liquid fertilizer," RSC Adv., vol. 7, no. 50, pp. 31244-31251, 2017. 
[61] S. Zhang et al., "Spatially resolved ozone densities and gas temperatures in a time modulated RF driven atmospheric pressure plasma jet: An analysis of the production and destruction mechanisms," J. Phys. D: Appl. Phys., vol. 46, no. 20, May 2013, Art. no. 205202.

[62] S. Iseni et al., "Nitric oxide density distributions in the effluent of an RF argon APPJ: Effect of gas flow rate and substrate," New J. Phys., vol. 16, no. 12, Dec. 2014, Art. no. 123011.

[63] S. Zhang, "Atmospheric pressure RF plasma jet: Characterization of flow and $\mathrm{O}_{2}$ chemistry," Technische Universiteit Eindhoven, Eindhoven, The Netherlands, Tech. Rep., 2015.

[64] K. K. Griendling et al., "Measurement of reactive oxygen species, reactive nitrogen species, and redox-dependent signaling in the cardiovascular system: A scientific statement from the American heart association," Circulation Res., vol. 119, no. 5, pp. e39-e75, 2016.

[65] M. P. Skatchkov et al., "Validation of lucigenin as a chemiluminescent probe to monitor vascular superoxide as well as basal vascular nitric oxide production," Biochem. Biophys. Res. Commun., vol. 254, no. 2, pp. 319-324, Jan. 1999.

[66] K. J. Nelson et al., "Use of dimedone-based chemical probes for sulfenic acid detection: Methods to visualize and identify labeled proteins," in Methods Enzymology. Amsterdam, The Netherlands: Elsevier, 2010, pp. 95-115.

[67] V. A. Tyurin et al., "Oxidative lipidomics of apoptosis: Quantitative assessment of phospholipid hydroperoxides in cells and tissues," Free Radicals Antioxidant Protocols. New York, NY, USA: Springer, 2010, pp. 353-374.

[68] G. He, "Electron paramagnetic resonance oximetry and redoximetry," in Advanced Protocols in Oxidative Stress II. New York, NY, USA: Springer, 2010, pp. 85-105.

[69] J. Sun, X. Zhang, M. Broderick, and H. Fein, "Measurement of nitric oxide production in biological systems by using griess reaction assay," Sensors, vol. 3, no. 8, pp. 276-284, Aug. 2003.

[70] K. H. Schoenbach, M. Moselhy, and W. Shi, "Self-organization in cathode boundary layer microdischarges," Plasma Sources Sci. Technol., vol. 13, no. 1, p. 177, 2004.

[71] S. Stauss, H. Muneoka, N. Ebato, F. Oshima, D. Z. Pai, and K. Terashima, "Self-organized pattern formation in helium dielectric barrier discharge cryoplasmas," Plasma Sources Sci. Technol., vol. 22, no. 2, Apr. 2013, Art. no. 025021.

[72] J. L. Walsh and M. G. Kong, "Contrasting characteristics of linear-field and cross-field atmospheric plasma jets," Appl. Phys. Lett., vol. 93, no. 11, Sep. 2008, Art. no. 111501

[73] K. H. Schoenbach, R. P. Joshi, R. H. Stark, F. C. Dobbs, and S. J. Beebe, "Bacterial decontamination of liquids with pulsed electric fields," IEEE Trans. Dielectrics Electr. Insul., vol. 7, no. 5, pp. 637-645, Oct. 2000

[74] B. Benstaali, D. Moussa, A. Addou, and J.-L. Brisset, "Plasma treatment of aqueous solutes: Some chemical properties of a gliding arc in humid air," Eur. Phys. J. Appl. Phys., vol. 4, no. 2, pp. 171-179, Nov. 1998.

[75] P. Attri et al., "Influence of ionic liquid and ionic salt on protein against the reactive species generated using dielectric barrier discharge plasma," Sci. Rep., vol. 5, no. 1, p. 17781, Dec. 2015.

[76] Z. Chen, X. Cheng, L. Lin, and M. Keidar, "Cold atmospheric plasma discharged in water and its potential use in cancer therapy," J. Phys. D: Appl. Phys., vol. 50, no. 1, Jan. 2017, Art. no. 015208.

[77] C. A. J. van Gils, S. Hofmann, B. K. H. L. Boekema, R. Brandenburg, and P. J. Bruggeman, "Mechanisms of bacterial inactivation in the liquid phase induced by a remote RF cold atmospheric pressure plasma jet," J. Phys. D: Appl. Phys., vol. 46, no. 17, May 2013, Art. no. 175203.

[78] P. Heirman, W. Van Boxem, and A. Bogaerts, "Reactivity and stability of plasma-generated oxygen and nitrogen species in buffered water solution: A computational study," Phys. Chem. Chem. Phys., vol. 21, no. 24, pp. 12881-12894, 2019.

[79] J. Benedikt et al., "The fate of plasma-generated oxygen atoms in aqueous solutions: Non-equilibrium atmospheric pressure plasmas as an efficient source of atomic $\mathrm{O}_{(\mathrm{aq})}$," Phys. Chem. Chem. Phys., vol. 20, no. 17, pp. 12037-12042, 2018.

[80] A. Privat-Maldonado, Y. Gorbanev, S. Dewilde, E. Smits, and A. Bogaerts, "Reduction of human glioblastoma spheroids using cold atmospheric plasma: The combined effect of short-and long-lived reactive species," Cancers, vol. 10, no. 11, p. 394, Oct. 2018.

[81] P. J. Bruggeman et al., "Plasma-liquid interactions: A review and roadmap," Plasma Sources Sci. Technol., vol. 25, no. 5, 2016, Art. no. 053002 .
[82] S. Samukawa et al., "The 2012 plasma roadmap," J. Phys. D: Appl. Phys., vol. 45, no. 25, 2012, Art. no. 253001.

[83] Y. Zhu, C. Li, H. Cui, and L. Lin, "Feasibility of cold plasma for the control of biofilms in food industry," Trends Food Sci. Technol., vol. 99, pp. 142-151, May 2020.

[84] J. M. Pérez-Andrés, C. Álvarez, P. J. Cullen, and B. K. Tiwari, "Effect of cold plasma on the techno-functional properties of animal protein food ingredients," Innov. Food Sci. Emerg. Technol., vol. 58, Dec. 2019, Art. no. 102205 .

[85] M. Gavahian and P. J. Cullen, "Cold plasma as an emerging technique for mycotoxin-free food: Efficacy, mechanisms, and trends," Food Rev. Int., vol. 36, no. 2, pp. 193-214, Feb. 2020.

[86] B. Surowsky, O. Schlüter, and D. Knorr, "Interactions of non-thermal atmospheric pressure plasma with solid and liquid food systems: A review," Food Eng. Rev., vol. 7, no. 2, pp. 82-108, Jun. 2015.

[87] M. R. Khani, B. Shokri, and K. Khajeh, "Studying the performance of dielectric barrier discharge and gliding arc plasma reactors in tomato peroxidase inactivation," J. Food Eng., vol. 197, pp. 107-112, Mar. 2017.

[88] G. G. Bălan et al., "Plasma-activated water: A new and effective alternative for duodenoscope reprocessing," Infection Drug Resistance, vol. 11, p. 727, May 2018.

[89] T. Xia et al., "Inactivation of airborne porcine reproductive and respiratory syndrome virus (PRRSv) by a packed bed dielectric barrier discharge non-thermal plasma," J. Hazardous Mater, vol. 393, Jul. 2020, Art. no. 122266.

[90] M. Selcuk, L. Oksuz, and P. Basaran, "Decontamination of grains and legumes infected with aspergillus spp. and penicillum spp. by cold plasma treatment," Bioresource Technol., vol. 99, no. 11, pp. 5104-5109, Jul. 2008.

[91] E. Toole, S. Hendricks, H. Borthwick, and V. K. Toole, "Physiology of seed germination," Аnnu. Rev. plant Physiol., vol. 7, no. 1, pp. 299-324, 1956.

[92] M. Kawakami, Y. Yamashita, M. Iwamoto, and S. Kagawa, "Modification of gas permeabilities of polymer membranes by plasma coating," J. Membrane Sci., vol. 19, no. 3, pp. 249-258, Jun. 1984.

[93] K. Kučerová, M. Henselová, L. Slováková, and K. Hensel, "Effects of plasma activated water on wheat: Germination, growth parameters, photosynthetic pigments, soluble protein content, and antioxidant enzymes activity," Plasma Processes Polym., vol. 16, no. 3, Mar. 2019, Art. no. 1800131.

[94] D. P. Park et al., "Reactive nitrogen species produced in water by nonequilibrium plasma increase plant growth rate and nutritional yield," Current Appl. Phys., vol. 13, pp. S19-S29, Mar. 2013.

[95] K. Takaki et al., "Improvements in plant growth rate using underwater discharge," J. Phys. Conf. Ser., vol. 418, Feb. 2013, Art no. 012140.

[96] L. Sivachandiran and A. Khacef, "Enhanced seed germination and plant growth by atmospheric pressure cold air plasma: Combined effect of seed and water treatment," RSC Adv., vol. 7, no. 4, pp. 1822-1832, 2017.

[97] U. Schnabel et al., "Plasma-treated air and water-assessment of synergistic antimicrobial effects for sanitation of food processing surfaces and environment," Foods, vol. 8, no. 2, p. 55, 2019.

[98] H. I. Yong et al., "An innovative curing process with plasma-treated water for production of loin ham and for its quality and safety," Plasma Processes Polym., vol. 15, no. 2, Feb. 2018, Art. no. 1700050.

[99] P. Bourke, D. Ziuzina, D. Boehm, P. J. Cullen, and K. Keener, "The potential of cold plasma for safe and sustainable food production," Trends Biotechnol., vol. 36, no. 6, pp. 615-626, Jun. 2018.

[100] N. N. Misra, S. K. Pankaj, A. Segat, and K. Ishikawa, "Cold plasma interactions with enzymes in foods and model systems," Trends Food Sci. Technol., vol. 55, pp. 39-47, Sep. 2016.

[101] F. Judée, S. Simon, C. Bailly, and T. Dufour, "Plasma-activation of tap water using DBD for agronomy applications: Identification and quantification of long lifetime chemical species and production/consumption mechanisms," Water Res., vol. 133, pp. 47-59, Apr. 2018.

[102] K. Takaki, N. Hayashi, D. Wang, and T. Ohshima, "High-voltage technologies for agriculture and food processing," J. Phys. D: Appl. Phys., vol. 52, no. 47, Nov. 2019, Art. no. 473001.

[103] I. K. Naumova, A. I. Maksimov, and A. V. Khlyustova, "Stimulation of the germinability of seeds and germ growth under treatment with plasma-activated water," Surf. Eng. Appl. Electrochem., vol. 47, no. 3, pp. 263-265, Jun. 2011.

[104] Q. Zhang et al., "A study of oxidative stress induced by nonthermal plasma-activated water for bacterial damage," Appl. Phys. Lett., vol. 102, no. 20, May 2013, Art. no. 203701. 
[105] Y. Tian et al., "Assessment of the physicochemical properties and biological effects of water activated by non-thermal plasma above and beneath the water surface," Plasma processes Polym., vol. 12, no. 5, pp. 439-449, 2015.

[106] K. Oehmigen, M. Hähnel, R. Brandenburg, C. Wilke, K.-D. Weltmann, and T. von Woedtke, "The role of acidification for antimicrobial activity of atmospheric pressure plasma in liquids," Plasma Processes Polym., vol. 7, nos. 3-4, pp. $250-257$, Mar. 2010

[107] P. Sun et al., "Inactivation of bacillus subtilis spores in water by a direct-current, cold atmospheric-pressure air plasma microjet," Plasma Processes Polym., vol. 9, no. 2, pp. 157-164, Feb. 2012.

[108] M. R. Vaka et al., "Towards the next-generation disinfectant: Composition, storability and preservation potential of plasma activated water on baby spinach leaves," Foods, vol. 8, no. 12, p. 692, Dec. 2019

[109] D. Chen et al., "Deoxynivalenol decontamination in raw and germinating barley treated by plasma-activated water and intense pulsed light," Food Bioprocess. Technol., vol. 12, no. 2, pp. 246-254, Feb. 2019.

[110] E. S. Inguglia, M. Oliveira, C. M. Burgess, J. P. Kerry, and B. K. Tiwari, "Plasma-activated water as an alternative nitrite source for the curing of beef jerky: Influence on quality and inactivation of listeria innocua," Innov. Food Sci. Emerg. Technol., vol. 59, Jan. 2020, Art. no. 102276.

[111] A. I. Muhammad et al., "Effects of plasma-activated water and blanching on microbial and physicochemical properties of tiger nuts," Food Bioprocess. Technol., vol. 12, no. 10, pp. 1721-1732, Oct. 2019.

[112] M. Naïtali, G. Kamgang-Youbi, J.-M. Herry, M.-N. Bellon-Fontaine, and J.-L. Brisset, "Combined effects of long-living chemical species during microbial inactivation using atmospheric plasma-treated water," Appl. Environ. Microbiol., vol. 76, no. 22, pp. 7662-7664, Nov. 2010.

[113] E. J. Choi et al., "Sequential application of plasma-activated water and mild heating improves microbiological quality of ready-to-use shredded salted kimchi cabbage (Brassica pekinensis L.)," Food Control, vol. 98, pp. 501-509, Apr. 2019.

[114] W. Frazier and D. Westhoff, "Food as a substrate for microorganism," in Food Microbiology. New Delhi, India: Tata McGraw-Hill, 1988, pp. 98-111.

[115] J. Qian et al., "Action of plasma-activated lactic acid on the inactivation of inoculated Salmonella Enteritidis and quality of beef," Innov. Food Sci. Emerg. Technol., vol. 57, Oct. 2019, Art. no. 102196.

[116] P. Lukes, B. R. Locke, and J.-L. Brisset, "Aqueous-phase chemistry of electrical discharge plasma in water and in gas-liquid environments," Plasma Chem. Catal. Gases liquids, vol. 1, pp. 243-308, Aug. 2012.

[117] P. Shaw et al., "Bacterial inactivation by plasma treated water enhanced by reactive nitrogen species," Sci. Rep., vol. 8, no. 1, pp. 1-10, Dec. 2018

[118] M. Schmidt et al., "Plasma-activation of larger liquid volumes by an inductively-limited discharge for antimicrobial purposes," Appl. Sci., vol. 9 , no. 10 , p. $2150,2019$.

[119] J. Zińczuk et al., "Antioxidant barrier, redox status, and oxidative damage to biomolecules in patients with colorectal cancer. Can malondialdehyde and catalase be markers of colorectal cancer advancement?" Biomolecules, vol. 9, no. 10, p. 637, Oct. 2019.

[120] D. Xu et al., "Mechanism of unprecedented hydroxyl radical production and site-specific oxidative DNA damage by photoactivation of the classic arylhydroxamic acid carcinogens," Carcinogenesis, vol. 40, no. 9, pp. 1153-1163, Dec. 2019.

[121] L. Cui, H. Huang, P. Ding, S. Zhu, W. Jing, and X. Gu, "Cogeneration of $\mathrm{H}_{2} \mathrm{O}_{2}$ and $\mathrm{OH}$ via a novel $\mathrm{Fe}_{3} \mathrm{O}_{4} / \mathrm{MWCNT}$ composite cathode in a dual-compartment electro-fenton membrane reactor," Separat. Purification Technol., vol. 237, Apr. 2020, Art. no. 116380.

[122] U. Nayek, V. K. Unnikrishnan, A. A. Abdul Salam, S. Chidangil, and D. Mathur, "Thermal energy electrons and $\mathrm{OH}$-radicals induce strand breaks in DNA in an aqueous environment: Some salts offer protection against strand breaks," J. Phys. Chem. A, vol. 124, no. 8, pp. 1508-1514, Feb. 2020.

[123] G. Bauer, "The synergistic effect between hydrogen peroxide and nitrite, two long-lived molecular species from cold atmospheric plasma, triggers tumor cells to induce their own cell death," Redox Biol., vol. 26, Sep. 2019, Art. no. 101291.

[124] L. McFerson, "Understanding ORP's role in the disinfection process," Water Eng. Manage., vol. 140, pp. 29-31, Dec. 1993.

[125] R. Thirumdas et al., "Plasma activated water (PAW): Chemistry, physico-chemical properties, applications in food and agriculture," Trends Food Sci. Technol., vol. 77, pp. 21-31, Jul. 2018.

[126] S. Elbashir, S. Parveen, J. Schwarz, T. Rippen, M. Jahncke, and A. DePaola, "Seafood pathogens and information on antimicrobial resistance: A review," Food Microbiol., vol. 70, pp. 85-93, Apr. 2018.
[127] A. Los, D. Ziuzina, D. Boehm, P. J. Cullen, and P. Bourke, "A comparison of inactivation efficacy and mechanisms of gas plasma and plasma activated water against aspergillus flavus spores and biofilms," Appl. Environ. Microbiology, vol. 86, pp. e02619-1-e02619-19, Feb. 2020.

[128] R. Ma, G. Wang, Y. Tian, K. Wang, J. Zhang, and J. Fang, "Nonthermal plasma-activated water inactivation of food-borne pathogen on fresh produce," J. Hazardous Mater., vol. 300, pp. 643-651, Dec. 2015.

[129] G. Cebrián, N. Sagarzazu, R. Pagán, S. Condón, and P. Mañas, "Development of stress resistance in staphylococcus aureus after exposure to sublethal environmental conditions," Int. J. Food Microbiol., vol. 140, no. 1, pp. 26-33, May 2010.

[130] X. Liao et al., "Application of atmospheric cold plasma-activated water (PAW) ice for preservation of shrimps (Metapenaeusensis)," Food Control, vol. 94, pp. 307-314, Dec. 2018.

[131] H. Seo et al., "Potential of non-thermal N2 plasma-treated buffer (NPB) for inhibiting plant pathogenic bacteria and enhancing food storage," $L W T$, vol. 125, May 2020, Art. no. 109210.

[132] C. Chen et al., "The effects of cold plasma-activated water treatment on the microbial growth and antioxidant properties of fresh-cut pears," Food Bioprocess Technol., vol. 12, no. 11, pp. 1842-1851, Nov. 2019.

[133] M. Gavahian, F. H. Sheu, M. J. Tsai, and Y. H. Chu, "The effects of dielectric barrier discharge plasma gas and plasma-activated water on texture, color, and bacterial characteristics of shiitake mushroom," J. Food Process. Preservation, vol. 44, no. 1, p. e14316, 2020.

[134] P. J. Cullen et al., "Translation of plasma technology from the lab to the food industry," Plasma Processes Polym., vol. 15, no. 2, Feb. 2018, Art. no. 1700085.

[135] J. M. Pérez-Andrés, M. de Alba, S. M. Harrison, N. P. Brunton, P. J. Cullen, and B. K. Tiwari, "Effects of cold atmospheric plasma on mackerel lipid and protein oxidation during storage," $L W T$, vol. 118 , Jan. 2020, Art. no. 108697

[136] F.-G. C. Ekezie, D.-W. Sun, and J.-H. Cheng, "A review on recent advances in cold plasma technology for the food industry: Current applications and future trends," Trends Food Sci. Technol., vol. 69, pp. 46-58, Nov. 2017.

[137] C. Pignata, D. D'Angelo, E. Fea, and G. Gilli, "A review on microbiological decontamination of fresh produce with nonthermal plasma," J. Appl. Microbiol., vol. 122, no. 6, pp. 1438-1455, Jun. 2017.

[138] C. Hertwig, N. Meneses, and A. Mathys, "Cold atmospheric pressure plasma and low energy electron beam as alternative nonthermal decontamination technologies for dry food surfaces: A review," Trends Food Sci. Technol., vol. 77, pp. 131-142, Jul. 2018.

[139] Z. Chen, "Cold atmospheric plasma with self-organized patterns for cancer therapy," Frontiers Nanosci. Nanotechnol., vol. 5, no. 1, pp. 1-4, 2019.

[140] D. B. Graves, "Reactive species from cold atmospheric plasma: Implications for cancer therapy," Plasma Processes Polym., vol. 11, no. 12, pp. 1120-1127, Dec. 2014.

[141] Z. Chen et al., "A novel micro cold atmospheric plasma device for glioblastoma both in vitro and in vivo," Cancers, vol. 9, no. 12, p. 61, May 2017.

[142] Z. Chen, L. Lin, X. Cheng, E. Gjika, and M. Keidar, "Effects of cold atmospheric plasma generated in deionized water in cell cancer therapy," Plasma Processes Polym., vol. 13, no. 12, pp. 1151-1156, Dec. 2016

[143] N. K. Kaushik et al., "Biological and medical applications of plasmaactivated media, water and solutions," Biol. Chem., vol. 400, no. 1, pp. 39-62, Dec. 2018.

[144] T. Takebe et al., "Vascularized and functional human liver from an iPSC-derived organ bud transplant," Nature, vol. 499, no. 7459, pp. 481-484, Jul. 2013.

[145] H. Masumoto et al., "Human iPS cell-engineered cardiac tissue sheets with cardiomyocytes and vascular cells for cardiac regeneration," Sci. Rep., vol. 4, no. 1, p. 6716, May 2015.

[146] H. Kamao et al., "Characterization of human induced pluripotent stem cell-derived retinal pigment epithelium cell sheets aiming for clinical application," Stem Cell Rep., vol. 2, no. 2, pp. 205-218, Feb. 2014.

[147] R. Matsumoto et al., "Plasma-activated medium selectively eliminates undifferentiated human induced pluripotent stem cells," Regenerative Therapy, vol. 5, pp. 55-63, Dec. 2016.

[148] T. Adachi, H. Tanaka, S. Nonomura, H. Hara, S.-I. Kondo, and M. Hori, "Plasma-activated medium induces A549 cell injury via a spiral apoptotic cascade involving the mitochondrial-nuclear network," Free Radical Biol. Med., vol. 79, pp. 28-44, Feb. 2015.

[149] M. Nakagawa et al., "A novel efficient feeder-free culture system for the derivation of human induced pluripotent stem cells," Sci. Rep., vol. 4, no. 1, p. 3594, May 2015. 
[150] H. Tanaka et al., "Plasma-activated medium selectively kills glioblastoma brain tumor cells by down-regulating a survival signaling molecule, AKT kinase," Plasma Med., vol. 1, nos. 3-4, pp. 265-277, 2011.

[151] K. Torii et al., "Effectiveness of plasma treatment on gastric cancer cells," Gastric Cancer, vol. 18, no. 3, pp. 635-643, Jul. 2015.

[152] Q. Zhang et al., "Sterilization efficiency of a novel electrochemical disinfectant against staphylococcus aureus," Environ. Sci. Technol., vol. 50, no. 6, pp. 3184-3192, Mar. 2016.

[153] J. Veits et al., "Newcastle disease virus expressing h5 hemagglutinin gene protects chickens against newcastle disease and avian influenza," Proc. Nat. Acad. Sci. USA, vol. 103, no. 21, pp. 8197-8202, May 2006.

[154] X. Su et al., "Inactivation efficacy of nonthermal plasma-activated solutions against Newcastle disease virus," Appl. Environ. Microbiol., vol. 84, no. 9, pp. e02836-1-e02836-17, 2018.

[155] H. Yasuda, T. Miura, H. Kurita, K. Takashima, and A. Mizuno, "Biological evaluation of DNA damage in bacteriophages inactivated by atmospheric pressure cold plasma," Plasma Processes Polym., vol. 7 , nos. 3-4, pp. 301-308, Mar. 2010.

[156] P. E. Petersen, "The world oral health report 2003: Continuous improvement of oral health in the 21st century-The approach of the WHO global oral health programme," Community Dentistry Oral Epidemiol., vol. 31, no. s1, pp. 3-24, Dec. 2003.

[157] Y. Li et al., "In vitro studies of the antimicrobial effect of nonthermal plasma-activated water as a novel mouthwash," Eur. J. Oral Sci., vol. 125, no. 6, pp. 463-470, Dec. 2017.

[158] G. Ye et al., "Treatment of oral pathogenic bacteria with non-thermal plasma activated water as a new type mouthwash," in Proc. Abstracts IEEE Int. Conf. Plasma Sci., 2013.

[159] J. Chauvin, F. Judee, N. Merbahi, and P. Vicendo, "Effects of plasma activated medium on head and neck FaDu cancerous cells: Comparison of 3D and 2D response," Anti-Cancer Agents Medicinal Chem., vol. 18, no. 6, pp. 776-783, Nov. 2018.

[160] G. Bauer, "Targeting protective catalase of tumor cells with cold atmospheric plasma-activated medium (PAM)," Anti-Cancer Agents Medicinal Chem., vol. 18, no. 6, pp. 784-804, 2018.

[161] D. Boehm, J. Curtin, P. J. Cullen, and P. Bourke, "Hydrogen peroxide and beyond-The potential of high-voltage plasma-activated liquids against cancerous cells," Anti-Cancer Agents Medicinal Chem., vol. 18, no. 6, pp. 815-823, Nov. 2018.

[162] P. Attri, J. H. Park, A. Ali, and E. H. Choi, "How does plasma activated media treatment differ from direct cold plasma treatment?" Anti-Cancer Agents Medicinal Chem., vol. 18, no. 6, pp. 805-814, Nov. 2018.

[163] P. Attri and A. Bogaerts, "Perspectives of plasma-treated solutions as anticancer drugs," Anti-Cancer Agents Medicinal Chem., vol. 19, no. 4, pp. 436-438, Jun. 2019.

[164] N. Kumar, P. Attri, S. Dewilde, and A. Bogaerts, "Inactivation of human pancreatic ductal adenocarcinoma with atmospheric plasma treated media and water: A comparative study," J. Phys. D: Appl. Phys., vol. 51, no. 25, Jun. 2018, Art. no. 255401.

[165] N. Kumar, J. H. Park, S. N. Jeon, B. S. Park, E. H. Choi, and P. Attri, "The action of microsecond-pulsed plasma-activated media on the inactivation of human lung cancer cells," J. Phys. D: Appl. Phys., vol. 49, no. 11, Mar. 2016, Art. no. 115401.

[166] T. Vos et al., "Global, regional, and national incidence, prevalence, and years lived with disability for 310 diseases and injuries, 1990-2015: A systematic analysis for the global burden of disease study 2015," The Lancet, vol. 388, no. 10053, pp. 1545-1602, 2016.

[167] W. Li et al., "Cold atmospheric plasma and iron oxide-based magnetic nanoparticles for synergetic lung cancer therapy," Free Radical Biol. Med., vol. 130, pp. 71-81, Jan. 2019.

[168] Z. Chen, "Development of new cold atmospheric plasma devices and approaches for cancer treatment," Ph.D. dissertation, George Washington Univ., Washington, DC, USA, 2018.

[169] Z. Chen et al., "Micro-sized cold atmospheric plasma source for brain and breast cancer treatment," Plasma Med., vol. 8, no. 2, pp. 203-215, 2018.

[170] Z. Chen, S. Zhang, I. Levchenko, I. I. Beilis, and M. Keidar, "Cancer inhibiting properties from self-organized plasma-liquid interface: In vitro demonstration," in Proc. IEEE Int. Conf. Plasma Sci., 2017.

[171] R.-G. Xu, Z. Chen, M. Keidar, and Y. Leng, "The impact of radicals in cold atmospheric plasma on the structural modification of gap junction: A reactive molecular dynamics study," Int. J. Smart Nano Mater. vol. 10, no. 2, pp. 144-155, Apr. 2019.

[172] D. B. Zolotukhin, L. Lin, E. Gjika, and M. Keidar, "Continuouswave plasma-generated electric field in 3D collagen gel during cold atmospheric plasma treatment," Plasma Processes Polym., vol. 16, no. 12, Dec. 2019, Art. no. 1900129 .
[173] E. Gjika et al., "Adaptation of operational parameters of cold atmospheric plasma and their role in cancer therapy," Clin. Plasma Med., vol. 9, pp. 16-17, Feb. 2018.

[174] E. Gjika, M. Kirschner, X. Cheng, Z. Chen, and M. Keidar, "An investigation of the immediate effect of cold atmospheric plasma on cancer cells," in Proc. IEEE Int. Conf. Plasma Sci., 2017.

[175] W. Tian and M. J. Kushner, "Atmospheric pressure dielectric barrier discharges interacting with liquid covered tissue," J. Phys. D: Appl. Phys., vol. 47, no. 16, Apr. 2014, Art. no. 165201.

[176] J. S. Beckman and W. H. Koppenol, "Nitric oxide, superoxide, and peroxynitrite: The good, the bad, and ugly," Amer. J. Physiol.-Cell Physiol., vol. 271, no. 5, pp. C1424-C1437, Nov. 1996.

[177] R. Kong et al., "Dihydroartemisinin enhances Apo2L/TRAIL-mediated apoptosis in pancreatic cancer cells via ROS-mediated up-regulation of death receptor 5," PLoS ONE, vol. 7, no. 5, May 2012, Art. no. e37222.

[178] R. Zhang, I. Humphreys, R. P. Sahu, Y. Shi, and S. K. Srivastava, "In vitro and in vivo induction of apoptosis by capsaicin in pancreatic cancer cells is mediated through ROS generation and mitochondrial death pathway," Apoptosis, vol. 13, no. 12, pp. 1465-1478, Dec. 2008.

[179] E. Freund et al., "Physical plasma-treated saline promotes an immunogenic phenotype in CT26 colon cancer cells in vitro and in vivo," Sci. Rep., vol. 9, no. 1, pp. 1-18, Dec. 2019.

[180] A. C. Gasparovic, M. Jaganjac, B. Mihaljevic, S. B. Sunjic, and N. Zarkovic, "Assays for the measurement of lipid peroxidation," Cell Senescence. New York, NY, USA: Springer, 2013, pp. 283-296.

[181] T. Grune, R. Shringarpure, N. Sitte, and K. Davies, "Age-related changes in protein oxidation and proteolysis in mammalian cells," J. Gerontol. A, Biol. Sci. Med. Sci., vol. 56, no. 11, pp. B459-B467, Nov. 2001.

[182] P. Chiarugi and T. Fiaschi, "Redox signalling in anchorage-dependent cell growth," Cellular Signalling, vol. 19, no. 4, pp. 672-682, Apr. 2007.

[183] M. Obeid et al., "Calreticulin exposure is required for the immunogenicity of $\gamma$-irradiation and UVC light-induced apoptosis," Cell Death Differentiation, vol. 14, no. 10, pp. 1848-1850, 2007.

[184] M. Obeid et al., "Calreticulin exposure dictates the immunogenicity of cancer cell death," Nature Med., vol. 13, no. 1, pp. 54-61, Jan. 2007.

[185] S. J. Gardai et al., "Cell-surface calreticulin initiates clearance of viable or apoptotic cells through trans-activation of LRP on the phagocyte," Cell, vol. 123, no. 2, pp. 321-334, Oct. 2005.

[186] D. V. Krysko, A. D. Garg, A. Kaczmarek, O. Krysko, P. Agostinis, and P. Vandenabeele, "Immunogenic cell death and DAMPs in cancer therapy," Nature Rev. Cancer, vol. 12, no. 12, pp. 860-875, Dec. 2012.

[187] T. Yamazaki et al., "Defective immunogenic cell death of HMGB1deficient tumors: Compensatory therapy with TLR4 agonists," Cell Death Differentiation, vol. 21, no. 1, pp. 69-78, Jan. 2014.

[188] X.-M. Zhu et al., "High mobility group box-1 protein regulate immunosuppression of regulatory t cells through toll-like receptor 4," Cytokine. vol. 54, no. 3, pp. 296-304, Jun. 2011.

[189] H. Tanaka et al., "Non-thermal atmospheric pressure plasma activates lactate in ringer's solution for anti-tumor effects," Sci. Rep., vol. 6 , p. 36282, Nov. 2016.

[190] S. Bekeschus et al., "Hydrogen peroxide: A central player in physical plasma-induced oxidative stress in human blood cells," Free Radical Res., vol. 48, no. 5, pp. 542-549, May 2014.

[191] N. Yoshikawa et al., "Plasma-activated medium promotes autophagic cell death along with alteration of the mTOR pathway," Sci. Rep., vol. 10, no. 1, pp. 1-8, Dec. 2020.

[192] J. Liu et al., "Low-temperature plasma-activated medium inhibited invasion and metastasis of melanoma cells via suppressing the Wnt/Bcatenin pathway," Plasma Processes Polym., vol. 17, no. 1, Jan. 2020, Art. no. 1900060.

[193] G.-M. Xu, Y. Hao, M.-Y. Sun, J.-R. Liu, X.-M. Shi, and G.-J. Zhang, "Characteristics of plasma activated medium produced by atmospheric pressure helium plasma jet and its selective effect on malignant melanoma and normal fibroblast cells," IEEE Trans. Plasma Sci., vol. 48, no. 2, pp. 587-595, Feb. 2020 
[194] M. Nagaya, H. Hara, T. Kamiya, and T. Adachi, "Inhibition of NAMPT markedly enhances plasma-activated medium-induced cell death in human breast cancer MDA-MB-231 cells," Arch. Biochemistry Biophys., vol. 676, Nov. 2019, Art. no. 108155.

[195] M. Adhikari, B. Adhikari, N. Kaushik, S.-J. Lee, N. K. Kaushik, and E. H. Choi, "Melanoma growth analysis in blood serum and tissue using xenograft model with response to cold atmospheric plasma activated medium," Appl. Sci., vol. 9, no. 20, p. 4227, Oct. 2019.

[196] J.-W. Lee, S. J. Han, H. Y. Kang, S.-S. Wi, M.-H. Jung, and K. S. Kim, "On-off switching of cell cycle and melanogenesis regulation of melanocytes by non-thermal atmospheric pressure plasma-activated medium," Sci. Rep., vol. 9, no. 1, pp. 1-10, Dec. 2019.

[197] S. Mohades, M. Laroussi, J. Sears, N. Barekzi, and H. Razavi, "Evaluation of the effects of a plasma activated medium on cancer cells," Phys. Plasmas, vol. 22, no. 12, Dec. 2015, Art. no. 122001.

[198] J. Duan, X. Lu, and G. He, "The selective effect of plasma activated medium in an in vitro co-culture of liver cancer and normal cells," J. Appl. Phys., vol. 121, no. 1, Jan. 2017, Art. no. 013302.

[199] S. Takeda et al., "Intraperitoneal administration of plasma-activated medium: Proposal of a novel treatment option for peritoneal metastasis from gastric cancer," Ann. Surgical Oncol., vol. 24, no. 5, pp. 1188-1194, May 2017.

[200] K. Saito et al., "Tumor-selective mitochondrial network collapse induced by atmospheric gas plasma-activated medium," Oncotarget, vol. 7, no. 15, p. 19910, 2016.

[201] S. Bekeschus, A. Schmidt, F. Niessner, T. Gerling, K.-D. Weltmann, and $\mathrm{K}$. Wende, "Basic research in plasma medicine-A throughput approach from liquids to cells," JoVE (J. Visualized Exp.), vol. 129, p. e56331, Nov. 2017.

[202] M. Gülden, A. Jess, J. Kammann, E. Maser, and H. Seibert, "Cytotoxic potency of $\mathrm{H}_{2} \mathrm{O}_{2}$ in cell cultures: Impact of cell concentration and exposure time," Free Radical Biol. Med., vol. 49, no. 8, pp. 1298-1305, Nov. 2010

[203] K. Merker, N. Sitte, and T. Grune, "Hydrogen peroxide-mediated protein oxidation in young and old human MRC-5 fibroblasts," Arch. Biochem. Biophys., vol. 375, no. 1, pp. 50-54, Mar. 2000.

[204] F. Utsumi et al., "Effect of indirect nonequilibrium atmospheric pressure plasma on anti-proliferative activity against chronic chemoresistant ovarian cancer cells in vitro and in vivo," PLoS ONE, vol. 8, no. 12, Dec. 2013, Art. no. e81576.

[205] J. Winter et al., "Tracking plasma generated $\mathrm{H}_{2} \mathrm{O}_{2}$ from gas into liquid phase and revealing its dominant impact on human skin cells," J. Phys. D: Appl. Phys., vol. 47, no. 28, Jul. 2014, Art. no. 285401.

[206] B. Haertel, T. Von Woedtke, K.-D. Weltmann, and U. Lindequist, "Nonthermal atmospheric-pressure plasma possible application in wound healing," Biomolecules Therapeutics, vol. 22, no. 6, p. 477, 2014.

[207] A. T. Dharmaraja, "Role of reactive oxygen species (ROS) in therapeutics and drug resistance in cancer and bacteria," J. Medicinal Chem., vol. 60, no. 8, pp. 3221-3240, Apr. 2017.

[208] K. Li et al., "Target ROS to induce apoptosis and cell cycle arrest by 5,7-dimethoxy-1,4-naphthoquinone derivative," Bioorganic Medicinal Chem. Lett., vol. 28, no. 3, pp. 273-277, Feb. 2018.

[209] H. Tresp, M. U. Hammer, K.-D. Weltmann, and S. Reuter, "Effects of atmosphere composition and liquid type on plasma-generated reactive species in biologically relevant solutions," Plasma Med., vol. 3, nos. 1-2, pp. 45-55, 2013.

[210] N. Maheshwari, F. H. Khan, and R. Mahmood, "Pentachlorophenolinduced cytotoxicity in human erythrocytes: Enhanced generation of ROS and RNS, lowered antioxidant power, inhibition of glucose metabolism, and morphological changes," Environ. Sci. Pollut. Res., vol. 26, no. 13, pp. 12985-13001, May 2019.
[211] J. Shen et al., "Preferential production of reactive species and bactericidal efficacy of gas-liquid plasma discharge," Chem. Eng. J., vol. 362, pp. 402-412, Apr. 2019.

[212] A. Allawzi, H. Elajaili, E. F. Redente, and E. Nozik-Grayck, "Oxidative toxicology of bleomycin: Role of the extracellular redox environment," Current Opinion Toxicol., vol. 13, pp. 68-73, Feb. 2019.

[213] G. E. Conway et al., "Non-thermal atmospheric plasma induces ROS-independent cell death in U373MG glioma cells and augments the cytotoxicity of temozolomide," Brit. J. Cancer, vol. 114, no. 4 , pp. 435-443, Feb. 2016.

[214] S. Kalghatgi, G. Friedman, A. Fridman, and A. M. Clyne, "Endothelial cell proliferation is enhanced by low dose non-thermal plasma through fibroblast growth factor-2 release," Ann. Biomed. Eng., vol. 38, no. 3, pp. 748-757, Mar. 2010.

[215] A. Agarwal et al., "Curcumin induces apoptosis and cell cycle arrest via the activation of reactive oxygen species-independent mitochondrial apoptotic pathway in Smad4 and p53 mutated colon adenocarcinoma HT29 cells," Nutrition Res., vol. 51, pp. 67-81, Mar. 2018.

[216] B. Li et al., "Metformin induces cell cycle arrest, apoptosis and autophagy through ROS/JNK signaling pathway in human osteosarcoma," Int. J. Biol. Sci., vol. 16, no. 1, p. 74, 2020.

[217] M. A. Al-Hamamah et al., "Genetic and epigenetic alterations induced by the small-molecule panobinostat: A mechanistic study at the chromosome and gene levels," DNA Repair, vol. 78, pp. 70-80, Jun. 2019.

[218] A. E. Archibong, M. L. Rideout, K. J. Harris, and A. Ramesh, "Oxidative stress in reproductive toxicology," Current Opinion Toxicol., vol. 7, pp. 95-101, Feb. 2018.

[219] M. Ishaq, M. M. Evans, and K. K. Ostrikov, "Effect of atmospheric gas plasmas on cancer cell signaling," Int. J. Cancer, vol. 134, no. 7, pp. 1517-1528, Apr. 2014.

[220] G. Chen et al., "Transdermal cold atmospheric plasma-mediated immune checkpoint blockade therapy," Proc. Nat. Acad. Sci. USA, vol. 117, no. 7, pp. 3687-3692, Feb. 2020.

[221] S. P. Cregan, V. L. Dawson, and R. S. Slack, "Role of AIF in caspasedependent and caspase-independent cell death," Oncogene, vol. 23, no. 16, pp. 2785-2796, Apr. 2004.

[222] S.-C. Chiu et al., "Poly (ADP-ribose) polymerase plays an important role in intermittent hypoxia-induced cell death in rat cerebellar granule cells," J. Biomed. Sci., vol. 19, no. 1, p. 29, 2012.

[223] S. Arndt et al., "Cold atmospheric plasma, a new strategy to induce senescence in melanoma cells," Experim. Dermatol., vol. 22, no. 4 , pp. 284-289, Apr. 2013.

[224] H. J. Ahn et al., "Targeting cancer cells with reactive oxygen and nitrogen species generated by atmospheric-pressure air plasma," PLoS ONE, vol. 9, no. 1, Jan. 2014, Art. no. e86173.

[225] S. Kesavardhana and T.-D. Kanneganti, "Stressed-out ROS take a silent death route," Nature Immunol., vol. 19, no. 2, pp. 103-105, Feb. 2018.

[226] G. E. Conway et al., "Cold atmospheric plasma induces accumulation of lysosomes and caspase-independent cell death in U373MG glioblastoma multiforme cells," Sci. Rep., vol. 9, no. 1, pp. 1-12, Dec. 2019.

[227] T. Tokunaga et al., "Plasma-stimulated medium kills TRAIL-resistant human malignant cells by promoting caspase-independent cell death via membrane potential and calcium dynamics modulation," Int. J. Oncol., vol. 52, no. 3, pp. 697-708, Jan. 2018.

[228] J. C. Harley, N. Suchowerska, and D. R. McKenzie, "Cancer treatment with gas plasma and with gas plasma-activated liquid: Positives, potentials and problems of clinical translation," Biophys. Rev., vol. 12, pp. 989-1006, Aug. 2020. 